\title{
Ueber einige Eigenschaften des Hämoglobins und des Methämoglobins.
}

Von

W. Preyer.

Mit einer Spectrumtafel.

Bedenkt man, wie leicht das Hämoglobin in grossen Mengen dargestellt werden kann, wie viele durchaus verschiedene Angriffspuncte es der Untersuchung darbietet, dann muss man sich wundern den so überaus interessanten Stoff nicht gründlicher erforscht zu sehen. Selbst eine seiner auffallendsten Eigenthümlichkeiten, der Krystallformenreichthum, ist nur wenig gekannt. Ich finde trotz gewissenhaften Durchsuchens der Litteratur nur 47 Wirbelthierarten, deren Blutkrystalle gesehen worden sind (23 Säugethiere, 7 Vögel, 4 Reptilien, 1 Amphibie, 12 Fische); und nur bei zehn von diesen wurde das Krystallsystem ermittelt. Die Blutkrystalle des Menschen, des Hundes, des Meerschweinchens, des Kaninchens sind, wie von Lang feststellte, rhombisch, die der Katze nach Rollett, die des Pferdes, wie Funke darthat, die des Löwen, des Cuguars und einer Felisart (F. marmorata) ${ }^{1}$ ), wie ich neuerdings bei Untersuchung der ausserordentlich schönen Präparate des Herrn Th. Deecke in Lübeck gefunden habe, gleichfalls rhombisch, die des Eichhörnchens dagegen, wie von Lang zeigte, hexagonal. Von den Blutkrystallen, die ich ausser diesen, aber nur in kleinen Exemplaren in mikroskopischen Präparaten, gesehen habe, sind wahrscheinlich rhombisch: die eines Affen (Cynocephalus babuin) ${ }^{2}$ ), einer Fledermaus ${ }^{3}$ ), des Igels, des Schafs, des Schweines, des Steinkauzes ${ }^{4}$ ), des Frosches. Das Affenblut gab schon in der Kälte leicht lösliche, schwer krystallisirende,

1-4) Diese Präparate verdanke ich der Güte des Hrn. Geh.-Rath Max Schultze. 
rhombische 'Täfelchen, das Blut der Fledermaus dünne Täfelchen mit sehr spitzen Winkeln; Kunde sah hier Nadeln (Zeitschr. f. rat. Med. 1852, S. 285). Igelblut lieferte mir rechteckige verlängerte Prismen, die zwar schon in der Kälte leicht löslich sind, aber doch aus dem Blute des chloroformirten Thieres leicht krystallisirten, wie auch Bojanowsky sah, der sie abbildet (Zeitschr. f. wiss. Zool. XII, T. 30 F. 8). Schafblutkrystalle beobachtete ich nur in entgastem Blute; es waren Prismen. Schweineblutkrystalle sah zuerst und bildete mit Menschenblutkrystallen ab Hünefeld 1840 (Der Chemismus in der thierischen Organisation. Leipzig, 1840, S. 160 u. Taf.), also 7 Jahre vor Leydig, Reichert und Kölliker. Später sahen sie Funke (Zeitschr. f. rat. Med. 1852, S. 201), Teichmann (ib. 1853, S. 376), Klebs (Med. Centralbl. 1863, S. 852) und ich selbst. Ich führe dies ausdrücklich an, weil man das Schweineblut für unkrystallisirbar hielt. Es krystallisirt nur ausserordentlich sehwer, meistens intraglobulär - in jedem Blutkörperchen ein Prisma - doch sah Funke auch $\gg$ Netze von Krystallstäbchen«. Das Blut des Steinkauzes (Strix noctua) fand ich leicht, das des Frosches sehr schwer krystallisirbar. Ersteres lieferte mir vierseitige Tafeln, letzteres dünne Prismen, welche vierseitig zu sein scheiner. Von den anderen bisher gesehenen Blutkrystallen können ferner hexagonal sein die der Maus und des Hamsters. Ich erhielt jedoch aus dem Herzblute einer Maus nur feine Nadeln. Die Hämoglobinkrystalle vom Fuchs, IItis, Maulwurf, Murmelthier, Rind, Raben, Sperling, von der Taube, der Gans, der Ente, der Lerche und der Patte wurden zwar dargestellt, aber ebensowenig wie die zahlreichen Fischblutkrystalle genügend krystallographiseh untersucht; die meisten scheinen rhombisch zu sein. Die Angabe Lehmanns (Chem. pharm. Centralbl. 1853 S. 983), man fände zuweilen im Meerschweinchenblute reguläre Oktaëder ist unrichtig; weil man niemals einfach lichtbrechende Blutkrystalle sieht, ebenso sind Hoppe-Seylers Angabe (Handbuch 1865 S. 202), die Meerschweinchenblutkrystalle seien tetragonal und die frühere Meinung Funke's das Menschen- und Katzenhämoglobin krystallisire im monoklinen System längst widerlegt. Somit sind alle bisher genauer krystallographisch untersuchten Hämoglobine, bei aller Verschiedenheit der Form, doch rhombisch, mit einziger Ausnahme des Eichhörnchenhämoglobins. Dieses ist, wie man sich leicht überzeugen kann, hexag o nal, denn die sechsseitigen Säulen bleiben, wenn man sie zwischen gekreuzten Nicols durch die End- 
fläche ansieht in jeder Stellung dunkel, zugleich aber sind sie doppeltbręchend, sie können also nư hexagonal sein.

Was diese krystallographische Verschiedenheit der Hämoglobine selhst nahestehender Thiere besonders eigenthümlich erscheinen lässt, das ist die absolute Identität des spectroskopischen Verhaltens der Blutfarbstoffe die ganze Thierreihe vom Menschen bis zum Regenwurm hinab. Ich hąbe mich'zum Ueberfluss durch vergleichende Versuche überzengt, dass nicht nur diẹ Spectra des hexagonalen Eichhörnchenhämoglobins und des rhombischen Hundehämoglobins ${ }^{1}$ ), sondern auch deren Verhalten gegen reducirende Mittel und gegen Cyạnkalium völlig gleich sind. Es muss also in allen Hä moglobinen eine geschlossene sehr bewegliche Atomgruppe existiren, welche durch Zutritt und Entziehung des Sauerstoffs eine totale Umlagerung erfährt und dadurch die Farbenänderungen und die Absorptionserscheinungen des unzersetzten Blutroths bedingt. Bei einer solchen erstaunlichen Uebereinstimmung liegt der Gedanke nąhe, es möchte doch wohl die krystallographische Verschiedenheit nicht so ahsolut sein, wie es zuerst schien, es möchte vielleicht das hexagonale Krystallsystem nur eine besongdere Combination des rhombischen sein. Ich finde, dass eine solche Auffassung bereits ihren Vertreter hat. A. Schrauf (Jahrbuch für Mineralogie 1865, S. 46) zeigte, wie sich das hexagonale System geometrisch allerdings als eine Combination des rhombischen darstellen lässt (P. $\overline{\mathrm{P}} \infty$, mit der einzigen Bedingung, dass $\infty \mathrm{P}: \infty \mathrm{P}=60^{\circ}$ ). Ist dieser Nachweis richtig, so fällt wenigstens ein gewichtiger Grund gegen die Identität der Hämoglobine aller Thiere. Aber der Nachweis hält nicht Stich. Denn wenn die hexagonalen Formen noch so einfache Combinationen rhombischer sind, so lässt sich doch der fundamentale optische Unterschied beider Systeme nicht wegleugnen. Die rhombischen Hämoglobine sind optisch zweiaxig, die hexagonalen optisch einaxig.

Indessen die Verschiedenheit der Krystallform allein kann uns nicht zwingen, die Hämoglobine für verschiedene Stoffe zu halten, sie würde nur einen Fall von Polymorphismus bedingen; es sind vielmehr andere Eigenschaften, welche zu einer Sonderung der Hä-

1) Auch das Regenwurmblut, aus dem ich durch Verdunstung rothe prismatische Krystalle erhielt, zeigt dasselbe Spectrum. 
moglobine in vielleicht ebenso viele verschiedene Körper nöthigen, als es rothes Blut führende Thierarten giebt, so die Löslichkeit, die Krystallisirbarkeit, Hygroskopie, Härte. Mit diesen und anderen Eigenschaften des Hämoglobins habe ich im Laufe der letzten Jahre vielfach mich beschäftigt und ich theile im Folgenden einige Resultate meiner Beobachtungen und Versuche trotz ihrer Unvollständigkeit hauptsächlich deshalb mit, weil ich dadurch auch andere zum Studium des räthselhaften Körpers, mehr als es bisher der Fall war, zu veranlassen hoffe und weil sich in vielen Abhardlungen und selbst in den besten Lehrbüchern zahlreiche unrichtige Angaben über das Hämoglobin vorfinden, welche, wenn sie auch nicht alle namentlich angeführt werden, durch die folgende Darstellung meiner Untersuchungen ihre Erledigung finden, während andererseits Manches der Bestätigung harrende durch sie bestätigt wird.

Die Härte der Blutkrystalle ist nach der Thierart sehr verschieden, im Allgemeinen aber eine geringe. Frische Hämoglobinkrystalle sind weich. Wohl alle lassen sich durch schwachen Druck auf das Deckgläschen, unter dem sie liegen, zersprengen. Bei den prismatischen Krystallen, die hierbei häufig quer durchbrochen werden, sieht man, dass stets die Bruchfläche uneben und zwar meist splitterig ist. Quetscht man durch erneuten Druck auf das Deckglas auch die Krystallfragmente, so sieht man die ganze Krystallmasse in sehr kleine Partikel zerfällt, welche keine Spur von krystallinischer Structur erkennen lassen, doch aber das Licht doppelt brechen, während unveränderte Blutkörperchen einfach lichtbrechend sind. Stellt man derartige Versuche an, so ist es zweckmässig sich möglichst grosser Krystalle zu bedienen, welche in sehr wässerigem Weingeist auf den Objectträger gebracht werden. Auch die Meerschweinchenblutkrystalle zerfallen beim Druck in lauter kleine Körner. Dasselbe beobachtet man häufig ohne Druck bei Blutkrystallen, welche längere Zeit als mikroskopische Präparate in allerlei Conservirungsflüssigkeiten wohlverkittet bei Zimmerwärme aufbewahrt wurden. Die Körnchen sind rothgefärbt und zeigen sehr lebhafte Molecularbewegung. Will man daher mikroskopische Präparate von Blutkrystallen aufbewahren, so müssen sie dauernd im Kalten (z. B. im Keller) gehalten werden. 
Trotz ihrer im Allgemeinen sehr geringen Härte, ihrer Zerdrückbarkeit, sind doch die frischen Hämoglobinkrystalle weder besonders elastisch, noch biegsam und nicht dehnbar. Wenn in einem Blutkörperchen sich ohne Zerreissung ein Krystall bildet, so wird zwar häufig der Krystall durch die geringere Nachgiebigkeit der Blutkörperwand gebogen, aber nur sehr wenig: es tritt viel leichter ein Zerbrechen desselben ein. Owsjannikow hat diesen Vorgang beobachtet und gibt vortreffliche Abbildungen davon. (Bull. de l'Ac. de St. Pétersbourg. VIII, 561-572).

Wenn man in einem Tropfen Wasser, dem eine Spur Weingeist zugesetzt ist, Meerschweinchen- oder Hundeblutkrystalle betrachtet und Strömungen in dem Fluidum erzeugt, so wird man niemals eine Formveränderung, das Eindrücken eines Krystalles beobachten, welches durch den Anprall anderer Krystalle bedingt wäre. Es ist ein ganz anderes Bild als das der schwimmenden Blutkörperchen, welche in hohem Maasse elastisch, biegsam, geschmeidig sind.

Doch gelingt es auch bei den Blutkrystallen eigenthümliche Formveränderungen hervorzurufen, Quellungserscheinunge n besonderer Art. Reichert hat sie (Müllers Arch. 1849. S. 197) zuerst beobachtet und sehr genau beschrieben. Indessen sind seine sämmtlichen Angaben über die durch Säuren und Alkalien bewirkte, durch Wasser rückgängig gemachte Volumzunahme der Meerschweinchensphenoide ohne Beeinträchtigung der Krystallform, nur gültig für die längere Zeit mit Alkohol in Berührung gewesenen Blutkrystalle. Auch sind nur diese in höherem Grade elastisch, so dass sie durch Druck verbreitert werden und bei Nachlass des Druckes wieder ihre ursprüngliche Gestalt annehmen. Säuren oder Alkalien für sich bewirken keine derartigen Veränderungen. Desgleichen ist die sehr auffallende Reichertsche Beobachtung, dass Quellung erregende Säuren durch andere Säuren verdrängt werden können ohne Aenderung der Krystallgestalt nur auf die durch Alkohol veränderten Krystalle zu beziehen.

Das specifische Gewicht des Hämoglobins ist noch unbekannt. Das des Hundehämoglobins lässt sich in folgender Weise annähernd berechnen. Nach Pflüger (in diesem Archiv I, 1, 69) und Zuntz beträgt das specifische Gewicht des Hundeblutserum s ziemlich constant 1025 und das mittlere specifische Gewicht $\bar{b}$ gesunden Hundeblutes 1060. Nun ist der mittlere Hämoglobingehalt 
eben dieses Blutes mach allen vorhandenen guten Bestimmungen 13,92 Gewichtsprocent, also der Hämoglobingehalt $h$ von $100 \mathrm{Cc}$. Blut 14,75 Gr. Nach Pflüger und Kemmerich aber (1. c. S. 75) steigt das spec. Gew. des Blutes ziemlich genau proportional seinem $\mathrm{Hä-}$ moglobingehalt, folglich ist

$$
(b-s) c=h
$$

worin $c=0,4215$ angiebt, um wieviel der Gehalt von 100 Cc. Blut an Hämoglobin steigt, wenn das spec. Gew. um 1 steigt. Setzt man nun $\mathrm{h}=100$, so erhält man das spec. Gew. des trockenen Hämoglobins $=1,262$, wenn Wasser $=1$. Hijerbei ist vorausgesetzt, dass das specifische Gewicht derjenigen Bestandtheile der Blutkörper, welche nicht Hämoglobin sind, im feuchten Zustande gleich ist dem specifischen Gewichte des Serum. In 100, Gr, Hundeblut vom spec. Gew, 1066 fand ich 15,89 Gr. Hämoglobin, also in $100 \mathrm{Cc}$. 16,95 Gr. (Mittel aus 6 Bestimmungen). Hieraus ergiebt sich $\mathrm{c}=0,4134$ und $\frac{s e+100}{\mathrm{c}}=1267$ statt 1262. Die Werthe können selbstverständlich keine grosse Genauigheit beanspruchen, zeigen aber, wie ich glaube, dass das specifische Gewicht des trockenen Hämoglobins $z$ wischen 1,2 und 1,3 liegt. Wenn man den Fehlerquellen den grösstmöglichen Spielraum gestattet, werden diese Grenzen nicht leicht überschritten.

\section{Optisches Verhalten der Blutkrystalle.}

Wir unterscheiden hier die Pellucidität, die Lichtbrechung, den Glanz, die Farbe, das Spectrum.

Die Pellucidität findet man, wenn die Blutkrystalle noch im krystallwasserhaltigen Zustande ganz frisch betrachtet werden, bei allen Thierarten, die ich untersuchte, gleich. Die Krystalle sind stets so durchsichtig, dass man die Kanten und Ecken der vom Beschauer abgewendeten Seite deutlich durch die rothe Masse durchsieht. Beim Trocknen geht diese Erkennbarkeit der Form verloren; die Krystalle werden rissig, weniger durchscheinend, zuletzt vollkommen opak.

In Bezug auf das Lichtbrechungsvermögen der Hämoglobinkrystalle muss auf das Nachdrücklichste betont werden, dass, wie schon erwähnt wurde, alle ohne eine einzige Ausnahme doppeltbrechend sind. Es ist keine Thierart bekannt, welche reguläre Blutkrystalle lieferte. Auch die Meerschweinchenkrystalle bre- 
chen das Licht doppelt, wie die Betrachtung derselben zwischen zwei Nicolschen Prismen lehrt, und jede Bemerkung über das Unerwartete, dass ein so complicirter organischer Atomencomplex im regulären System krystallisire, beruht auf einem Irrthum.

Auch die verwitterten, glanzlosen jahrelang zwischen zwei Glasplatten trocken aufbewahrten Krystalle (vom Hunde) behalten ihr Vermëgen, das Licht doppelt zu brechen, indem sie zwischen gekreuzten Nicols leuchten.

Der Glanz, welchen frisch dargestellte Blutkrystalle zeigen, lässt sich am besten mit dem Glanze der Seide vergleichen. Hat man durch Vermischen des defibrinirten Blutes mit Wasser und Weingeist und Ablühlen des Gemenges eine höchst krystallreiche Emulsion sich dargestellt, so lässt jedes Aufwirbeln des Fluidums mit einem Glasstabe den prachtvollen Glanz der hochrothen Krystalle erkennen. Noch besser aber sieht man ihn, wenn die Blutkrystalle auf einer Glasplatte in der Kälte an der Luft von dem Wasser der Mutterlauge befreit worden sind. Durch die verschiedene Lage jedes einzelnen Kryställchens erhält dann die Fläche ganz das schöne Ansehen des rothen Damastes, zumal wenn directes Sonnenlicht darauf fällt. Ferner kann man sich von dem starken Seidenglanze der Blutkrystalle überzeugen, wenn man sie mit wenig Mutterlauge in einem Becherglase an den Wandungen hin und her schwenkt, während die Sonne oder eine stark leuchtende Lampenflamme durchscheint. Auch wenn die Krystalle klein sind, sieht man sie doch einzeln glitzern und das auffallende Licht stark reflectiren. Sowie die Verwitterung beginnt, hört jede Spur des Glanzes auf.

Die Farbe der Hämoglobinkrystalle ist im Allgemeinen die Blutfarbe. Auch die Verschiedenheiten dieser sind leicht an dem Blutroth selbst zu beobachten, vor allem der Unterschied der arteriellen und venösen Blutfarbe. Wenn, wie es bei den Darstellungen der Blutkrystalle im Grossen der Fall ist, der Sauerstoff der Luft freien Zutritt zu dem krystallisirenden Farbestoff hat, dann erhält man die intensiv arteriellroth gefärbten Krystalle des Sauerstoffhämoglobins. Werden diese Blutkrystalle, welche locker gebundenen Sauerstoff neben dem constitutionellen Sauerstoff enthalten, ohne sonst irgend eine Zersetzung zu erfahren, z. B. bei niedriger 'T'emperatur durch das Vacuum von dem locker gebundenen Sauerstoffe befreit, so erhält man die dunkler gefärbten Krystalle des sauer- 
stofffreien Hämoglooins. Sie sind jedoch nicht blos dunkler, sondern haben einen Stich ins Bläuliche, Purpurne erhalten und scheinen an den Kanten grün durch. Sie sind pleochromatisch. Da ich an ganz frischen Sauerstoffhämoglobinkrystallen vom Hunde keine Pleochromasie, insbesondere nicht die von Lang beschriebenen Farbenerscheinungen constatiren konnte, so muss ich annehmen, dass die von Lang untersuchten Präparate zum Theil sauerstofffrei waren. Ich finde die reducirten Hämoglobinkrystalle ausnahmslos pleochromatisch, die sauerstoffhaltigen nicht. Die Farbe ersterer ähnelt der des venösen, die letzterer der des arteriellen Blutes. Schüttelt man eine wässerige Lösung der Krystalle, welche noch ungelöstes krystallisirtes reducirtes Hämoglobin enthält, mit Luft, so geht die Pleochromasie verloren und es wird daraus wieder arteriellgefärbtes Sauerstoffhämoglobin. Auch die reine wässerige Lösung kann zu diesem Versuche verwendet werden, nur ist dann, weil es an den stark reflectirenden Theilchen der Flüssigkeit fehlt, der Unterschied, wenn auch bedeutend, doch nicht so schlagend.

Man erkennt jedoch leicht, dass die sauerstofffreien Lösungen dichroitisch, die sauerstoffhaltigen monochroitisch sind. Es ist lediglich die An- resp. Abwesenheit des Sauerstoffs, welche den Unterschied bedingt. Die Kohlensäure hat nichts damit zu thun, denn eine vollkommen gasfreie, also auch kohlensäurefreie Hämoglobinlösung ist ebenso dichroitisch wie eine mit Kohlensäure überladene sauerstofffreie. Dass Hämoglobin in venösem Blute, in einer Kohlensäure- oder Stickstoff-Atmosphäre eminent pleochroitisch, in einer Sauerstoffatmosphäre monochroitisch ist, zeigte zuerst unwiderleglich Brücke (Dichroismus des Blutfarbestoffs, Wien. Sitzungsber. 1853 Dec. XI, 1073). Rose (Caspers Vierteljahrschr. f. ger. Med. 1853, IV, 296) ist nicht der Entdecker der Dichromasie des Blutroths, sondern der Dichromasie des Hämatinalkalis.

\section{Das Spectrum des Hämoglobins.}

Reine Sauerstoffhämoglobinkrystalle von einem beliebigen Thiere entnommen zeigen feucht oder trocken an einer Glasplatte haftend, wenn man sie zwischen den Spalt eines Spectralapparates und die Sonne oder eine Lampenflamme bringt, im Spectrum zwei sehr charakteristische Absorptionstre ifen (Taf. IX Fig. 3 bis 7). Es sind dieselben, welche Hoppe-Seyler an dem mit Wasser an der Luft 
stark verdünnten Blute rothblütiger Thiere entdeckte. Er fand (1862), dass die Streifen noch erkennbar sind, wenn $1 \mathrm{Gr}$. trockenen Sauerstoffhämoglobins in $10000 \mathrm{Cc}$. Wasser in einer Schicht von $1 \mathrm{Cm}$. vom directen Sonnenlicht durchstrahlt wird (Med. ch. Unters. II, 199). Ich bin bei meinen Versuchen zur Bestimmung der Färbekraft des Hämoglobins, welche, wie die folgende Darstellung zeigt, von denen Hoppe-Seylers zum Theil erheblich abweichen, in diesem Puncte doch zu demselben Resultat gekommen, dass nämlich eine Sauerstoffhämoglobinlösung von $0,01 \%$ noch deutlich unter den angegebenen Bedingungen die Streifen erkennen lüsst. Verdünnt man noch weiter, so wird zuerst der bei $\mathrm{E}$ gelegene Absorptionstreifen ausgelöscht und noch bei einer Verdünnung bis auf 3 bis 9 tausendtel Procent bleibt der andere sichtbar (Taf. IX Fig. 2). Ich habe keinen Unterschied in dem spectroskopischen Verhalten reiner wässeriger Sauerstoffhämoglobinlösungen und wässeriger Lösungen arteriellen Blutes beobachtet. Die Abbildungen auf Taf. IX (Fig. 2 bis 10) beziehen sich daher auf beide: Lösungen von 0,003 bis 0,009 Procent zeigen nur einen Absorptionstreifen und diesen sehr schwach (Taf.IX Fig. 2), Lösungen von $0,01 \%$ zeigen zwei Absorptionsbänder, beide schwach (Fig. 3), Lösungen von $0,09 \%$ zeigen beide Streifen, namentlich den ersten $\alpha$, dunkler und den zweiten $\beta$ breiter (Fg. 4). Lösungen von $0,16 \%$ zeigen schon eine starke Absorption des Violett. Beide Streifen sind sehr viel dunkler und breiter geworden (Fig. 5). Bei einer Concentration von $0,3 \%$ reicht der Streif $\alpha$ schon bis an die Linie D (Fig. 6), beide Streifen sind noch dunkler und noch breiter geworden, das Violett ist ganz, Blau (auch bei absolut reinen Sauerstoffhämoglobinlösungen) zum Theil absorbirt. Nimmt die Concentration nun bis auf $0,6 \% \mathrm{zu}$, dann rücken die beiden Streifen, sich immer mehr verbreiternd, einander näher und erscheinen schliesslich $(0,6 \%)$ nur noch gerade getrennt (Fig. 7$)$. Lösungen von $0,8 \%$ )

1) Diese Lösung bildet die Normallösung bei meiner Methode zur quantitativen Bestimmung des Hämoglobins durch das Spectrum (Ann. d. Chemie u. Pharm. 1866, Dec.). Man kann das Verfahren auch benutzen, um die gesammte Blutmenge eines Thieres genauer, als es bisher möglich war, zu bestimmen, indem man zuerst das Thier verbluten lässt, sämmtliches Blut $\mathrm{p}$ sammelt und seinen Gehalt an Hämoglobin $\mathrm{h}$ ermittelt, dann von der Aorta und mehreren andern Stellen aus die Blutgefässe mit halbprocentiger Kochsalzlösung so lange auswäscht, bis die Salzlösung farblos 
zeigen (Fig. 8) dann nur noch ein breites schwarzes Feld, die beiden Absorptionsbänder sind zusammengeflossen und ausser dem Roth (von a bis gegen D) sieht man nur noch einen grünen Streifen (zwischen $b$ und $\mathbf{F}$ bei b). Lösungen von $0,9 \%$ (Fig. 9) zeigen diesen grünen Streifen nicht mehr, solche von $0,7 \%$ lassen ihn viel heller erscheinen. Wenn man jetzt die Concentration der Hämoglobinlösung immer mehr zunehmen lässt, so tritt keine weitere Veränderung ein, als eine Verengung des rothen Feldes von beiden Seiten. Vermischt man beliebiges frisches mit Sauerstoff gesättigtes Blut mit soviel destillirtem Wasser, dass eine $1 \mathrm{Cm}$. dicke Schicht der Lösung überhaupt Licht durchlässt, dann sieht man einen ganz schmalen sehr schattigen rothen Streifen in der Nähe von $\mathrm{C}$ und die Lösung enthält etwas mehr als $7 \%$ Hämoglobin bei $100^{\circ}$ trocken. Blutlösungen, welche mehr als $7,3 \%$ Hämoglobin enthalten, lassen in centimeterdicker Schicht gar kein Licht durch und erst solche von $5,4 \%$ zeigen einen deutlich rothen Streifen (Fig. 10) und zwar gerade an der Stelle im Spectrum, welche bei zersetzten Sauerstoffhämoglobinlösungen auch bei starker Verdünnung verdunkelt zu sein pflegt (Hämatinstreifen, Säurebänder, Methämoglobin).

Zwei volle Jahre nachdem Hoppe-Seyler die Beschreibung der Sauerstoffhämoglobinstreifen bekannt gemacht hatte ('Arch. f. pathol. Anat. u. Physiol. 1862, XXIII, 446-449), wurde erst herausgefunden, dass der Gehalt des Hämoglobins an locker gebundenem Sauerstoff einen fundamentalen Einfluss auf das Spectrum hat. Stokes war es, der am 16. Juni 1864 der Royal society (Philos. Mag. Ser. 4. XXVIII, Nr. 190, Nov. 1864, 391-400) diese von ihm entdeckte Thatsache mittheilte. Stokes fand bekanntlich, „dass das Hämoglobin in zwei Zuständen der Oxydation existirt, welche dureh die Farbe und das Spectrum unterscheidbar sind; dass das sauerstofthaltige Hämoglobin durch reducirende Stoffe in das sauerstofffreie und umgekehrt dieses durch Schütteln mit atmosphärischer Luft wieder in Sauerstoffhämoglobin umgewandelt werden kann."

Die Krystalle des sauerstofffreien Hämoglobins, welche W. Kühne zuerst untersuchte und welche in dem durch die Luftleere entgasten

abläuft. Sämmtliches Waschwasser wird sorgfältig gesammelt und sein Hämoglobingehalt $h^{\prime}$ bestimmt, dann ist die Gesammtblutmenge des Thieres $B=\frac{p\left(h+h^{\prime}\right)}{h}$. 
Blute entstehen, zeigen einen breiten sollecht begrenzten Absorptionstreifen zwischen $D$ und $\mathrm{E}$. Es ist das von Stokes entdeckte Reductionsband (Taf. IX. Fig. 11). Seine dunkelste Stelle liegt genau in der Mitte zwischen $\mathrm{D}$ und $\mathrm{E}$. Wenn man eine Sauerstoffihämoglobinlösung durch das Vacuum oder ein farbloses reducirendes Agens z. B. Natriumsulphid oder Zinnoxydul oder durch Wasserstoffgas reducirt, so bemerkt man ausserdem, dass viel mehr Blau und weniger Grün sichtbar wird, als in einer Sauerstoffhämoglobinlösung gleicher Concentration, Dicke der Schicht etc. Ferner ist, wie Stokes ganz richtig angiebt, das Licht, welches beim Concentriren der Lösung zuletzt übrig bleibt, beim Sauerstoff hämoglobin neben Roth Grün, beim reducirten neben Roth Blau.

Endlich ist auch Hoppe-Seylers Angabe leicht zu bestätigen, der zu Folge eine bedeutend stärkere Absorption des äussersten Roth durch reducirtes:Hämoglobin, als durch sauerstoffhaltiges stattfindet, wenn die Versuchsbedingungen in beiden Fällen sonst idie gleichen sind.

Die chemische Reaction des Sauerstoffhämoglobins.

Taucht man in eine verdünte, kalte, wässerige, absolut reine Lösung von ganz frisch dargestelltem Sauerstoffhämoglobin rothes Lacmuspapier oder Curcumapapier, so beobachtet man daran keine anderen Veränderungen als nach dem Eintauchen in neutrales destillirtes Wasser. Sehr empfindliches blaues Cyminpapier dagegen wird gebleicht und sehr empfindliches blanes Laemuspapier wird violett gefärbt, das Sauerstoffhämoglobin reagirt also schwach sauer. Die saure Reaction lässt sich sehr schlagend in folgender Weise darthun: Man schneide aus blauem Lacmuspapier ein kleines Filter und giesse darauf eine wässerige durchaus reine Sauerstoffhämoglobinlösung. Man wasche es vollkommen aus mit destillirtem Wasser und zwar ebensolang oder länger als man nöthig hat, um ceteris paribus ein Filter von weissem Papier wieder farblos zu machen, so wird das ganze Filterchen roth, und bleibt auch beim hartnäckigsten Auswaschen roth, zeigt aber, wenn lange genug ausgewaschen wurde, nicht das Hämoglobinspectrum. Bringt man nun eine Sauerstoffhämoglobinlösung darauf, welche eine höchst geringe Menge Soda enthält, so wird das Filterchen wieder blau trotz der rothen Farbe der Lösung, und bleibt beim aahaltenden Auswaschen mit destillir- 
tem Wasser blau; man sieht also, dass die Roth- resp. Violettfarbung des ursprünglich blauen Lacmuspapiers nicht nach dem Auswaschen noch von der rothen Farbe des Hämoglobins ableitbar ist; überdies zeigen dic Versuche mit Curcuma- und gebleichtem Cyaninpapier, die nicht gefärbt werden, während das blaue Lacmuspapier geröthet wird, die Unhaltbarkeit eines solchen Einwurfes.

Das Sauerstoffhämoglobin ist eine schwache Säure. Auch ohne Lacmus oder Cyanin lässt sich die saure Natur des Sauerstoffhämoglobins nachweisen. A. Schmidt beobachtete (Hämatol. Stud. S. 117, 118) zuerst und A. Rollett bestätigte die Thatsache, dass in dem durch einen constanten Strom zerlegten Blute das Hämoglobin unzersetzt in Krystallen am positiven Pole sich ausscheidet. Ferner bekunden die von mir angestellten Versuche über die Einwirkung reinsten Sauerstoffhämoglobins auf Natriumcarbonat, dass auch in der Kälte Kohlensäure daraus entwickelt wird (Med. Centralbl. 1867).

Zuntz meint (Physiologie des Blutes. Inaug. Diss. S. 19, 1868 Bonn), nur die zersetzten Hämoglobinkrystalle reagirten sauer, da die Röthung seines mit Kochsalz getränkten Lacmuspapiers erst nach 1 bis 2 Minuten eintrat. Vielleicht erfordert die Imbibition unter jenen Umständen allein diese Zeit.

\section{Die Löslichkeit der Blutkrystalle.}

Alle bis. jetzt untersuchten Hämoglobine sind im frischen und krystallinischen Zustande in Wasser löslich. Aber die Löslichkeit der aus verschiedenen Thieren gewonnenen Blutkrystalle ist eine sehr verschiedene. Manche, wie z. B. die des Rindes, zerfliessen an der Luft, andere, wie die des Raben, sind nach Bojanowsky in kaltem Wasser ganz ungemein schwer löslich und widerstehen selbst dem warmen Wasser längere Zeit. Und zwischen diesen Extremen liegen die manchfaltigsten Uebergänge. Hoppe-Seyler fand dass 100 Cc. Wasser bei $5^{0} \mathrm{C} .2 \mathrm{Gr}$. trockenes Hundehämoglobin lösen.

Nach C. Schmidt lösen

100 Gr. Wasser bei $18^{\circ}$ C. 12,20 Gr. wasserfr. Hämogl. vom Hunde. 100 Gr. Wasser bei $18^{\circ}$ C. 15,59 Gr. kryst. Hämogl.

Diese Angaben sind ungenau, denn das von C. Schmidt untersuchte Hämoglobin war mit Blutbestandtheilen verunreinigt, welche 
einen Einfluss auf die Löslichkeit haben können: Diese ist für reines Wasser geringer.

Auch hat die Temperatur einen ganz ausserordentlichen EinHuss auf die Löslichkeit reiner Hämoglobine in Wasser.

Die Löslichkeit nimmt äusserst schnell mit der Temperatur zu und zwar, wie ich mich überzeugt habe, beim Hundeblutfarbstoff bis zu $54^{\circ}$, vielleicht aber bis gegen $60^{\circ} \mathrm{C}$.

Die grossen Unterschiede, welche Lehmann fand, als er die Löslichkeit des Hundehämoglobins in Wasser zu ermitteln suchte, sind zum Theil, wie er selbst bemerkt, auf Zersetzung der Krystallsubstanz zurückzuführen, zum Theil aber auch auf die Unreinheit derselben und vor allem auf die Temperatur. Es ist erstaunlich, dass Lehmann bei keiner Bestimmung der Löslichkeit die Temperatur angegeben hat. 100 Theile Wasser lösen nach seinen Versuchen 0,4 bis 3,1 Theile Hundehämoglobin (bei $120^{\circ}$ trocken).

Nach einer anderen Angabe von Lehmann lösen sich die Blutkrystalle des Hundes erst in ihrem 96fachen .Gewicht Wasser (bei welcher Temperatur?), nach Böttcher in ihrem 6 bis 8fachen Gewichte Wasser. Auch hier fehlt die Temperaturangabe.

Nach Lehmann löst sich ferner $1 \mathrm{Th}$. trockene Krystallsubstanz vom Meerschweinchen in 597 Th. Wasser. Auch die Eichhörnchenblutkrystalle sind sehr schwer löslich.

Durch längere Berührung mit Alkohol werden sowohl die Meerschweinchenblutkrystalle als auch die Hundeblutkrystalle in Wasser schwerer löslich, und zwar um so schwerer löslich, je concentrirter der Alkohol. Absoluter Alkohol macht sie ganz unlöslich.

In sehr wässerigem Weingeist sind indessen die Hundeblutkrystalle leicht löslich und diese Lösungen sind viel haltbarer als rein wässerige. Durch einen mehrstündigen Aufenthalt aber auch in ganz verdünntem Weingeist werden die Hämoglobinkrystalle in Wasser schwerer löslich.

In absolutem Alkohol kann man sie sehr lange ohne auffallende Formveränderung aufbewahren, die Farbe, der Glanz, die doppelte Lichtbrechung gehen aber verloren.

In sehr verdünnten Lösungen von Albumin, auch in verdünnter Sodalösung löst sich das Hämoglobin, wie Hoppe-Seyler fand, viel leichter als in Wasser. Und diese Lösungen sind gleichfalls haltbarer als wässerige. 
In concentrirtem Alkohol, in Aether, in ätherischen und fetten Oelen ist Hämoglobin, wie C. Schmidt fand, unlöslich. Es sind ferner die reinen Blutkrystalle aus Hundeblut, wie ich finde, unlöslich in Benzol, Terpenthinöl, Chloroform, Kreosot, Amylalkohol, Schwefelkohlenstoff. Ueber das Verhalten dieser Flüssigkeiten zu Hämoglobin in seiner wässerigen Lösung siehe unten.

Leichter löslich als in Wasser sind die Hundeblutkrystalle ohne sofortige Zersetzung in höchst verdünnter Kalilauge, Natronlauge, in sehr stark verdünntem Ammoniakwasser, in Barytwasser, Kalkwasser, in mässig concentrirter und verdünnter Lösung von Kaliumcarbonat, Kaliumbicarbonat, Natriumcarbonat, Natriumbicarbonat, Ammoniumcarbonat, Ammoniumbicarbonat, Natriumphosphat, Ammoniumphosphat, Natriumborat. In allen diesen alkalischen Lösungen tritt aber nach wenigen Tagen auch in der Kälte $\left(9^{\circ}\right)$ ohne Trübung eine Zersetzung ein.

Von Säuren kann ich nicht eine als Lösungsmittel des Hämoglobins bezeichnen, denn selbst die in der Kälte und bei gewöhnlicher Temperatur sehr schwer löslichen bewirken dennoch in wässeriger Lösung schneller als reines Wasser bei gewöhnlicher Temperatur Zersetzung, so z. B. Benzoesäure, Harnsäure, Hippursäure, Gallussäure, Glykocholsäure, Borsäure. In diesen saıren Lösungen tritt nach einigen Stunden in der Zimmerwärme ohne Trübung Zersetzung ein. Ich komme darauf zurück.

In frischem normalem menschlichem Harn, in wässerigen Harnstoff-, Rohrzucker-, Milchzucker-, Traubenzucker-Lösungen, in Glycerin, in Galle, in Hydroceleflüssigkeit, in Blutserum sind die Sauerstoffhämoglobinkrystalle in der Kälte ohne sofortige Zersetzung leicht löslich. Sie sind endlich bei gewöhnlicher Temperatur ohne Veränderung der Absorptionstreifen im Spectrum, ohne Trübung oder sonstige Zersetzung in den Salzlösungen löslich, welche weiter unten angefuihrt werden.

\section{Diffundibilität.}

Obwohl das Hämoglobin ein krystallisirbarer Körper ist, somit zu den krystalloiden Substanzen Grahams gehört und daher im Dialysor durch Pergamentpapier diffundiren müsste, wenn Grahams Theorie richtig wäre, so ist dieses doch nicht der Fall. Das Hämoglobin geht, wie W. Kühne zeigte und wie ich mich selbst über- 
zeugte, nicht durch Pergamentpapier hindurch. Kühne fand, dass es weder zu Wasser, noch zu Säuren, noch zu Alkalien übergeht, und dass dasselbe für Auflösungen des zersetzten Hämoglobins in Säuren und Alkalien gilt. Die Versuche A: Schmidts, welcher das Diffusionsvermögen des Hämoglobins gross fand, sind daher auf die geringere Güte des angewandten Pergamentpapiers oder Durchlöcherung der Membran zu schieben. Da ferner A. Schmidt im Gegensatz zu anderen Forschern auch einen Albuminstoff, nämlich das "Globulin", diffundibel fand, so dass er Gerinnung in einer fibrinogenen Flüssigkeit beobachtete, wenn eine fibrinoplastische in der Grahamschen Zelle sich befand, so ist die Vermuthung gerechtfertigt, auch hier habe nur die Mangelhaftigkeit des Pergamentpapiers oder die Ungleichmässigkeit der Schweinsblase oder selbst die Methode der Befestigung beider den Durchtritt ermöglicht ${ }^{1}$ ). Unrichtig ist ferner die Bemerkung A. Schmidts, das "Globulin", welches diffundire, sei in seiner Verbindung mit dem seiner Meinung nach fibrinoplastisch wirkenden Hämoglobin krystallisirbar und dem entsprechend sei das Diffusionsvermögen des letzteren ein grosses. Denn es wirkt, wie Kühne fand, das gereinigte Hämoglobin nicht im Mindesten fibrinoplastisch. Ich habe mit reinen Hämoglobinkrystallen aus Hundeblut und ganz frischer (absolut blutfreier) Hydroceleflüssigkeit vom Menschen sehr zahlreiche Gemenge in den allerverschiedensten Verhältnissen bereitet und niemals (bei Temperaturen zwischen $0^{\circ}$ und $50^{\circ}$ ) auch nur die allergeringste Fibrinbildung beobachtet. Die Lösungen bleiben vollkommen klar, während dieselbe Hydroceleflüssigkeit mit unreinen Blutkry, allen versetzt schon bei $20^{\circ} \mathrm{C}$. in wenigen Minuten ein Coagulum ausscheidet, an dem beiläufig bemerkt constant Gasblasen hängen. A. Schmidt hat daher gewiss mit unreiner Krystallsubstanz experimentirt und ich stehe nicht an, als eine der empfindlichsten Methoden eine Verunreinigung der Hämoglobinkrystalle mit Blutkörperchen zu erkennen, das Verhalten zu einer frischen Hydroceleflüssigkeit aufzustellen. Spuren von beigemengten Blutkörperchen (vielleicht nur farblosen?) genügen zur Erzeugung des Gerinnsels.

1) Es ist häufig beim Grahamschen Dialysor sehr schwer eine Undichtigkeit zu erkennen. Ich finde beim Dialysiren von Blut-, Zuckerharn- und Curarelösungen in dem Farbstoff ein sicheres Kriterium und möchte bej farblosen Flüsssigkeiten den Zusatz eines nicht diffundirenden Farbstoffs empfehlen. 
Einwirkung der Wärme auf das Hämoglobin.

Werden feuchte Blutkrystalle unter oder bei $0^{\circ}$ getrocknet, so behalten sie ihre hellrothe Farbe und lösen sich vollständig in Wasser zu einer arteriellrothen Flüssigkeit auf, die sich wie eine Lösung frischer Blutkrystalle verhält. Ja das unter $0^{\circ}$ getrocknete Hämoglobin kann, wenn es vollständig trocken war, auf $100^{\circ}$ einige Stunden lang erhitzt werden, ohne sich merklich zu zersetzen, wie Hoppe-Seyler bemerkt. Zur Zersetzung bei gewöhnlicher 'Temperatur ist Wasseraufnahme nicht erforderlich, denn auch die bei oder besser unter $0^{0}$ vollständig getrockneten Hämoglobinkrystalle, wenn sie sich auch lange Zeit im Exsiccator an der Luft unzersetzt erhalten, werden doch schliesslich zersetzt, dunkelgefärbt und zwar bei gewöhnlicher Temperatur.

Erwärmt man sofort die feuchten Krystalle oder lässt man sie nur in vacuo oder an der Luft im Exsiccator sogleich über $0^{0}$ trocknen, so zersetzen sie sich ehe sie trocken sind, sie werden missfarbig braunroth und lösen sich nicht mehr vollständig in Wasser, es entsteht Methämoglobin und ein noch nicht näher untersuchter weisser in Wasser unlöslicher Albuminstoff, welcher vollkommen auf Platin verbrennt, ohne die geringste Spur von Asche zu hinterlassen und welchen ich Globin ${ }^{1}$ ) nenne.

Erhitzt man die feuchten Krystalle auf Platinblech, so werden sie fast augenblicklich dunkelrothbraun, fast schwarz gefärbt, die Masse bläht sich auf, verbrennt beim Anzünden mit stark leuchtender Flamme und riecht wie verbrennende stickstoffhaltige thierische Theile, z. B. Fleisch. Nach dem Verbrennen und Glühen bleibt Eisenoxyd zurück, welches in Salpetersäure gelöst nur dann, wenn die Krystalle nicht rein waren, mit Ammoniummolybdat ver-

1) Das Globin ist derselbe Körper, von dem Hoppe - Seyler fand, dass er in Kochsalzlösung schleimig quillt, ohne sich zu lösen. Ebenso verhält er sich in Sodalösungen. In sehr verdünnter Salzsäure löst sich nur eine Spur. Beim Kochen in Wasser wird das Globin fester und zngleich weniger pellucid. Der Unterschied ist sehr auffallend. Bei weiterem Kochen zertheilen sich die Flöckchen sehr fein und es erhält die Emulsion, in der das unbewaffnete Auge keine festen Theilchen mehr erkenut, ein opalescirendes Ansehen. Eisessig in grossem Ueberschuss dazu gebracht löst das Globin mur scheinbar auf. Denn aus der wasserhellen Lösung scheiden sich die weissen Flocken nach einigen Tagen wieder aus. Globin ist das einzige bekannte reine Albumin. 
setzt eine gelbe Färbung zeigt. In diesem Falle ist ausser dem Eisenoxyd Phosphorsäure in der Asche. Es gelingtaber nur sehr schwer und mit ungeheurem Substanzverlust Hämoglobin darzustellen, dessen Asche die Phosphorsäurereaction nicht gibt. Da sich ausser dem Eisen kein Metall in der Hämoglobinasche nachweisen lässt, so ist ohne Zweifel die Verunreinigung der Krystalle, die Phosphorsäure in der Asche hinterlassen, von einem phosphorhaltigen organischen Bestandtheile des Blutkörperchenstroma abzuleiten, dessen Phosphor beim Veraschen zu Phosphorsäure oxydirt wurde.

Das Meerschweinchenhämoglobin fängt nach Lehmann bei $160^{\circ}$ bis $170^{\circ}$ an sich zu zersetzen; entwickelt einen Geruch nach verbranntem Horn, aber in geringerem Grade als Eiweissstoffe; bläht sich stark auf und entwickelt bei stärkerem Erhitzen soviel beim Entzünden starkleuchtende Dämpfe, wie verbrennendes Fett (Lehmann).

Wässerige Lösungen des Hämoglobin haben bekanntlich die Eigenschaft beim Erwärmen wie Eiweiss zu coaguliren. Es ist jedoch nicht das Hämoglobin selbst, welches gerinnt, sondern es sind coagulabele eiweissartige Zersetzungsproducte, in welche das Hämoglobin beim Erwärmen zerfällt, wie schon die gleichzeitige Ausscheidung des Hämatin beweist.

Die wässerige Lösung reiner Meerschweinchenblutkrystalle fängt bei $62^{\circ} \mathrm{C}$. an zu opalesciren, bei $63,5^{\circ} \mathrm{C}$. ist die Coagulation vollendet (Lehmann). Das Coagulum ist schwer filtrirbar. Die wässerige Lösung der Hundeblutkrystalle fängt nach Lehmann zu geriunen an zwischen 64 u. $65^{\circ}$. C. Schmidt gibt an, dass wässerige Hundehämoglobinlösungen bei $72^{\circ}$ sich zu trüben beginnen und über $80^{\circ}$ rothbraune in verdünntem Alkali mit tiefblutrother Farbe leicht lösliche Flocken ausscheiden. Neutralisire man diese Lösung mit Essigsäure, so werden sie gefällt, im geringsten Ueberschuss der Essigsäure aber wieder gelöst. Ich kann mir die Schmidtschen Angaben, die sehr weit von meinem Befunde abweichen, nur durch starke Verunreinigung des Materials erklären. Ich fand bei vielen Versuchen mit wässerigen Lösungen vollkommen reiner Krystalle aus Hundeblut, dass sie stets genau bei $64^{0}$ sich zu trüben beginnen. Wann aber die Coagulation beendigt ist, das haben die Versuche nicht mit Sicherheit ergeben. Soviel steht nur fest, dass, wenn die Lösungen einige Minuten einer Temperatur von $68,5^{\circ}$ ausgesetzt gewesen sind, das Filtrat farblos wird und nicht mehr gerinnt. Wenn 
aber die Lösung ganz allmählich von $0^{\circ}$ bis $64^{\circ}$ und weiter $65^{\circ}$ bis $68,5^{\circ}$ erwärmt wird und man filtrirt sie in dem Augenblick, da letztere Temperatur erreicht ist, so erhält man ein klares rothes Filtrat, welches deutlich die Sauerstoffhämoglobinstreifen zeigt und beim Erwärmen wieder genau bei $64^{\circ}$ sich trübt. Aus der Trübung gehen feine Flöckchen hervor, die sich zu grösseren zusammenballen und an der Oberfläche der Flüssigkeit schwimmen. Vielleicht haben die aus dem Hämoglobin sich abspaltenden Albumine verschiedene zwischen 64 und $68,5^{\circ}$ liegende Gerinnungstemperaturen. Ein sehr merkwürdiges Verhalten indess zeigen sie oder vielmehr ihr Generator das Hämoglobin, wenn der Lösung Soda zugesetzt wird. Erwärmt man eine wässerige Lösung von Blutkrystallen (Hund), der ein wenig Natriumcarbonat zugesetzt wurde, so tritt bekanntlich gar keine Gerinnung ein, auch wenn man bis $100^{\circ}$ erhitzt. Es tritt aber eine Zersetzung bei $54^{\circ}$ ein, im Vacuum ebenso wie an der Luft, die Farbe wird bei genau $54^{\circ}$ constant $d$ unkel, tief braunroth und die Lösung zeigt den Streifen des Hämatins in alkalischer Lösung und nicht mehr die Sauerstoffhämoglobinstreifen. Die Reaction der Flüssigkeit ist nach wie vor alkalisch und die Lösung bleibt auch nach anhaltendem Erhitzen vollkommen klar.

Hierdurch schien eine Methode gegeben zur Bestimmung des A equivalentgewichtes des Hämoglobin. Man könnte glauben, durch Ermittlung der zur Verhütung der Gerinnung gerade erforderlichen Natronmengen sei gefunden mit wieviel Natron eine bekannte Menge Hämoglobin zu einer nicht geriunenden Verbindung sich vereinige. Dem ist aber nicht so, denn, wie ich eben angab, tritt beim Erwärmen einer Soda enthaltenden Hämoglobinlösung eine Zersetzung bei $54^{\circ}$ ein, so zwar, dass unter Farbenänderung die Sauerstoffhämoglobinstreifen im Spectrum schwinden und eine $A b$ sorption im Roth bei $\mathrm{C}$ erscheint. Es ist daher wohl als sicher anzunehmen, dass bei dieser Temperatur eine Spaltung des Hämoglobins in Eiweissstoffe und einen Farbstoff (Hämatin) statthat und nur deshalb keine Trübung eintritt, weil die Eiweissstoffe mit Natron za Natronalbuminat verbunden sind und weil das Hämatin oder Hämatinnatron in einer wässerigen Lösung von Soda oder von Natronalbuminat löslich ist. Nichtsdestoweniger hielt ich es für interessant, die Menge Soda zu ermitteln, die zu einer wässerigen Hämoglobinlösung gesetzt werden muss, damit sie ihre Gerinnbarkeit verliere, schon weil die Existenz einer Verbindung des Hämoglobins 
mit Natron sehr wahrscheinlich ist. Ich kann von meinen Versuchen nur zwei als gelungen bezeichnen.

Eine wässerige Lösung reinsten Hämoglobins aus Hundeblut wurde hergestellt und ihr Gehalt an Hämoglobin (bei $100^{\circ}$ trocken) spectroskopisch ermittelt. Ich wandte Lösungen von genau 0,8 Proc. an. Ferner wurden mit allen erdenkbaren Vorsichtsmassregeln Lösungen von Natriumcarbonat bereitet und deren Gehalt durch Wägen in verschlossenen Gefüssen bestimmt. Diè erste dieser Lösungen enthielt 0.081851 , die andere genau 0.5 Proc. wasserfreies Natriumcarbonat $\left(\mathrm{Na}_{2} \mathrm{CO}_{3}\right)$. Die erste bereitete ich selbst, die zweite Herr Dr. Zuntz. Nun wurden stets zu genau $1,000 \mathrm{Cc}$. der rothen Lösung verschiedene Mengen der Sodalösung zugesetzt und zwar so lange; bis ein Augenblick erreicht war, wo keine Gerinnung des Gemisches mehr eintrat. Ich fand im 1. Versuch, dass 1 Cc. der Hämoglobinlösung mit 0.235 Cc. der 1. Sodalösung versetzt beim Erwärmen sich noch trübte, mit $0.240 \mathrm{Cc}$. versetzt blieb sie beim Erwärmen klar. Der Rechnung legte ich das Mittel 0.2375 Cc. zu Grunde. Der zweite Versuch mit einer anderen Hämoglobinlösung (gleichfalls von 0.8 Proc.) ergab, dass 1 Cc. Hämoglobinlösung mit 0.035 Cc. der 2. Sodalösung versetzt gerann, mit 0.040 Cc. klar blieb. Nur die über alles Lob erhabene Vorzüglichkeit der Pipetten aus Dr. Geisslers Werkstatt ermöglichte es mit Sicherheit 0.005 Cc. mehr oder weniger zuzusetzen. Die gefundenen Zahlen liefern nun folgendes Resultat: 1. Versuch. $0.008 \mathrm{Gr}$. Hämoglobin verlangen $0.000194 \mathrm{Gr}$. Natriumcarbonat, also $1,000 \mathrm{Gr}$. Hämoglobin $0,02429 \mathrm{Gr}$. Natriumcarbonat. 2. Versuch. 0.008 Gr. Hämoglobin verlangen 0.0001875 Gr. Soda, also 1,000 Gr. Hämoglobin $0.02343 \mathrm{Gr}$. Im Mittel verlangte demnach 1 Gr. Hämoglobin in destillirtem Wasser um nicht zu gerinnen 0.023868 Gr. Natriumcarbonat. Das Aequivalentgewicht des Natriumcarbonates beträgt, da nach Stas das Atomgewicht des Natrium = $23,04(0=16$ und $\mathrm{C}=12) 106,08$. Dieses würde unter der Annahme einfacher chemischer Bindung beim Erwärmen ohne Gerinnung ergeben für das Aequivalentgewicht des Hämoglobins $\frac{10608}{2,3868}$ $=4444,4$. Auffallender Weise ist nun 4444,4 fast genau ein Drittheil des Moleculargewichts, welches ich aus der procertischen Elementaranalyse des Hämoglobins ableitete, nämlich $13324{ }^{1}$ ). Es scheint

1) Die procentische Zusammensetzung des Hundehämoglobins ist im Mittel aus allen vorhandenen Analysen (von Hoppe-Seyler, C.Schmidt u. a.) diese: 
mir daher gerechtfertigt anzunehmen, dass 1 Mol. Hämoglobin, um in nicht gerinnbare Verbindungen überzugehen, 3 Mol. Natriumoxyd bedarf.

Einwirkung einiger Säuren auf Sauerstoffhämoglobin.

Alle Angaben über das Verhalten des Hämoglobins zu anderen Stoffen beziehen sich im Folgenden, wenn nicht ausdrücklich etwas anderes angegeben ist, auf Lösungen ganz frisch dargestellter vollkommen reiner Hundeblutkrystalle in kaltem destillirtem Wasser, die Theilstriche, mit denen die Absorptionstreifen bezeichnet sind, auf die Scala der beigegebenen Spectrumtafel (T. IX).

Die verschiedenen Säuren, über deren Verhalten zu SauerstoffhämogIobin ich zur vorläufigen Orientirung Versuche anstellte, sind folgende :

Chlorwasserstoffsäure.

Aeusserst geringe Mengen concentrirter Salzsäure bewirken einen anfangs farblosen eiweissartigen beim Schütteln sich wieder lösenden Niederschlag. Zugleich macht die blutrothe Farbe der Lösung einer dunkelbraunrothen Platz und im Spectrum gewahrt man ein Säureband von 41-51, die Sauerstoffstreifen sind verschwunden. Hat sich der anfangs entstandene Niederschlag gelöst und fügt man mehr Salzsäure hinzu, so entsteht eine reichliche Fällung, welche aber schon in der Kälte in überschüssiger Salzsäure (und auch in Essigsäure leicht)- löslich ist. Beim Kochen bleibt die Lösung klar.

\begin{tabular}{rcc}
$602 \mathrm{C}=7224$ & berechnet & gefunden \\
$960 \mathrm{H}=960$ & 54,22 & 54,00 \\
$154 \mathrm{~N}=2156$ & 7,20 & 7,25 \\
$1 \mathrm{Fe}=56$ & 16,18 & 16,25 \\
$3 \mathrm{~S}=96$ & 0,42 & 0,42 \\
$177 \mathrm{O}=2832$ & 0,72 & 0,63 \\
\hline 13324 & 21,26 & $(21,45)$ \\
\hline & 100,00 & 100,00
\end{tabular}

Die früher mitgetheilten Zahlen (Med. Centralbl. 1866 S. 324) sind nicht so genau. Sie erstreckten sich auf eine kleinere $Z$ ahl von Bestimmungen. Veberdies ist a. a. O. zu lesen S. 324 Z. 5 v. u. 2156 statt 2136 . S. 325 Z. 6 v. o. ist der Satz ,.Hieraus . . . gut stimmt" zu streichen. Endlich muss es heissen Z. 25 nicht „Berlin", sondern „Bo nn". 
Wendet man statt minimaler Mengen concentrirter, etwas grössere Mengen höchst verdünnter Salzsäure an, so kann man ohne jede Trübung die beschriebenen Veränderungen des optischen Verhaltens hervorrufen.

\section{Salp etersäure.}

Ein Tropfen gewöhnlicher Salpetersäure zu mehreren Cubiccentimetern concentrirter Hämoglobinlösung gebracht ruft darin sofort einen starken weisslichen eiweissartigen Nielerschlag hervor, welcher beim Umschütteln sich klar löst. . Zugleich wird die Lösung ausserordentlich dunkelbraunroth gefärbt, im Spectrum sind die Sauerstoffhämoglobinstreifen nicht mehr sichtbar, statt dessen ein Säureband (44-51). Setzt man zu der klaren Lösung mehr Salpetersäure, so entsteht ein voluminöser eiweissartiger Niederschlag, welcher sich in einem Ueberschuss von Salpetersäure beim Kochen (nicht in der Kälte) vollständig zu einer bräunlich-grünlichen, beim Verdünnen grünlichen Flüssigkeit langsam klar auflöst. Beim Abkühlen scheiden sich die in der Siedehitze gelöst gewesenen Flocken zum Theil wieder aus. Lehmann bemerkte, was richtig ist, dass die festen Blutkrystalle durch Salpetersäure sehr dunkel, fast schwarzgefärbt werden, und dass sie sich beim Erwärmen gelb färben und zu einer gelben Flüssigkeit auflösen.

Rauchende Salpetersäure in geringer Menge zu concentrirten Hämoglobinlösungen gebracht, ruft darin voluminöse Eiweissniederschläge hervor, welche im Ueberschuss des Fällungsmittels sich ohne Erwärmen über der Flamme vollständig autiösen. Die Lösung bleibt auch nach dem Erwärmen klar und wird gelblichgrün.

Höchst verdünnte Salpetersäure ruft keinen Niederschlag in wässerigen Blutrothlösungen hervor, färbt sie aber braun und löscht die Sauerstoffstreifen auch in der Kälte schnell aus. Die Lösung coagulirt nicht beim Erwärmen, sie bleibt vollkommen klar.

\section{Schwefelsäure.}

Sehr kleine Mengen stark verdünnter Schwefelsäure genügen zur Zersetzung grosser Hämoglobinmengen. Lässt man eine Spur kalter verdünnter Schwefelsäure zu der rothen Lösung fliessen, so wird in wenig Augenblicken die Farbe dunkelroth, dann nach und nach braungelbroth, zuletzt gelbbrraun. Man sieht die Sauerstoffhämoglobinstreifen allmählich schwinden und es tritt ein Säureband 
$(45-50)$ auf. Solche schwefelsaure Lösungen bleiben beim Erhitzen klar. Concentrirte Schwefelsäure ruft neben diesen Veränderungen, welche augenblicklich eintreten, eine Fällung hervor, die eiweissartig ist und beim Schütteln sich löst. Fügt man mehr Schwefelsäure zu, so entsteht ein voluminöser Niederschlag. Aber auch dieser ist im Ueberschusse concentrirter Schwefelsänre ohne Erwärmen über der Flamme leicht löslich. Er ist auch in concentrirter Essigsäure in der Kälte löslich, nicht, wie C. Schmidt angibt, unlöslich. Kocht man die klare schwefelsaure Lösung und lässt erkalten, so trübt sie sich nicht.

Phosphorsäure.

Concentrirte Auflösungen glasiger Phosphorsäure in Wasser rufen in minimalen Mengen voluminöse Niederschläge hervor und entfärben die Flüssigkeit. Sehr stark verdünnte wässerige Lösungen der glasigen Phosphorsäure bewirken auch in ganz verdünnten Hämoglobinlösungen Fällungen. Die Niederschläge sind röthlichgrau und flockig, sie lösen sich nicht im Ueberschuss der Säure, auch beim Kochen nicht.

Gewöhnliche Phosphorsäure dagegen, wenigstens solche von 1,130 spec. Gewicht, trübt die rothen Lösungen nicht, weder in der Kälte, noch beim Kochen. Es tritt nur stets fast augenblicklich eine Farbenänderung ein. Die Lösungen werdẹ erst dunkelroth dann braun, die Sauerstoffhämoglobinstreifen verschwinden und es erscheint ein Säureband (45-50).

Aus diesen Reactionen folgt, dass die gewöhnliche Phosphorsäure $\left(\mathrm{Ph} \mathrm{H}_{3} \mathrm{O}_{4}\right.$ in Wasser) das Hämoglobin nicht fällt, während Metaphosphorsäure $\left(\mathrm{PhHO}_{3}\right.$ in Wasser) es fällt, wie es auch C. Schmidt richtig angibt.

Schwefelige Säure.

Eine kleine Menge in Wasser gelöster schwefeliger Säure zu einigen Cubiccentimetern einer concentrirten Hämoglobinlösung gebracht, ruft darin keine Trübung, sondern nur sofortige Farbenveränderung hervor. Die Lösung wird braun und zeigt ein Säureband (45-50). Die Sauerstoffhämoglobinstreifen treten beim Verdünnen nicht wieder auf. Die braune schwefeligsaure Lösung bleibt beim Sieden und nachherigen Abkühlen klar. 
Phosphorige Säure.

Was von der schwefeligen Säure angegeben wurde, gilt auch für die phosphorige Säure. Nur das Säureband ist nicht ganz dasselbe, es erstreckte sich von $43-51$.

\section{Chromsäure.}

Kalte concentrirte wässẹrige Chromsäurelösungen rufen schon in Spuren eine Trübung und in kleinen Mengen einen voluminösen Niederschlag hervor, welcher in der Kälte in überschüssiger Chromsäure unlöslich ist, sich aber beim Kochen darin vollständig löst. Beim Abkühlen trüben sich die Lösungsgemische.

Wendet man kleine Mengen einer sehr stark verdünnten Chromsäure an, so entsteht eine beim Schütteln verschwindende Trübung, die Lösung wird braun, die Sauerstofthämoglobinstreifen verschwinden und es tritt ein Säureband auf. Solche Lösungen coaguliren nicht beim Kochen, sie bleiben auch beim Abkühlen klar.

Phosphormolybdänsäure.

(In salpetersaurer Lösung.)

Ein Tropfen Phosphormolybdänsäure ruft in verdünnten Hämoglobinlösungen eine Trübung, mehrere Tropfen in concentrirteren einen flockigen orangefarbigen Niederschlag hervor, welcher in der Kälte im Ueberschuss des Fällungsmittels (auch in destillirtem Wasser) unlöslich, sich langsam zu Boden setzt. Kocht man das mit überschüssiger Phosphormolybdänsäure versetzte Gemisch, so löst sich der Niederschlag auf unter Ausscheidung geringer Mengen einer schwarzen Substanz (Molybdän?).

\section{Borsäure.}

Wird eine Sauerstoffhämoglobinlösung mit kalt gesättigter wässeriger Borsäurelösung (etwa 3 Proc.) versetzt, so bleiben die Sauerstoffstreifen im Spectrum, die Farbe etc. unverändert. Erst nach sehr langer Zeit (im Vergleiche zu anderen Säuren) tritt Zersetzung ein, das Methämoglobinband erscheint. Es nimmt an Breite und Intensität, während die Lösung ruhig steht, allmählich zu (45-53). Uebrigens bleiben bei gewöhnlicher Temperatur die Sauerstoffstreifen noch tagelang, ja wochenlang sichtbar. Beim Erwärmen coagulirt die Lösung. Wenn man aber etwa 1 ' Th. fester Borsäure in etwa $3 \mathrm{Th}$. einer circa einprocentigen wässerigen Hämoglobinlösung bringt und erwärmt, so löst sich die Borsäure 
vollständig auf, die Sauerstoffstreifen verschwinden und man erhält eine braune Lösung, welche das Borsäureband (44-49) zeigt und ganz klar ist. Bein Abkühlen scheidet sich ein Gerinnsel und Borsäure gleichzeitig aus. Es entsteht ein Magma, so dass man die Probirröhre umkehren kann, ohne dass etwas ausfliesst. Lirwärmt man ohne Wasserzusatz, so erhält man eine klare braune Lösung wie vorher.

\section{Oxalsäure.}

Sehr wenig kalt gesättigte Oxalsäurelösung verändert in der Kälte in wenigen Augenblicken die Farbe der blutrothen Lösung, sie wird dunkelroth, dann dunkelrothbraun und es tritt sofort ein Säureband von 45-51 auf. Die oxalsauren Lösungen gerinnen beim Erwärmen nicht, sie bleiben beim Kochen klar und trüben sich nicht beim Abkühlen. Sehr ähnlich der Oxalsäure verhält sich die

Essigsäure.

Säureband $44-51$.

Meerschweinchenblutkrystalle lösen sich, wie Lehmann fand, in Essigsäure sehr leicht mit gelber Farbe auf und werden aus dieser Lösung in Flocken gefällt von rothem und gelbem Blutlaugensalz und durch Neutralisation.

Ausser dem Säureband, welches mit der Concentration oder der durchstrahlten Schicht der Lösung an Breite und Intensität wächst, sind noch zwei schlecht begrenzte Absorptionstreifen sichtbar, welche Stokes zuerst im essigsauren Cruorextract bemerkte und die ich durch Hinzufügen von Essigsäure zu concentrirten reinen wässerigen Hämoglobinlösungen gleichfalls hervorrufen konnte. Sie liegen bei $71-79$ und $86-96$; ausserdem ist eine ausserordentlich schwache Absorption bei 62-64 bemerkbar; das Säureband erstreckte sich bei diesen Messungen von 47-51, die Grenzen des sichtbaren Spectrum bei 37 und 127. Stokes sah diese Streifen auch dann, wenn das wässerige Cruorextract mit seinem Volumen Aether und dann ein wenig Eisessig versetzt wurde, in der sauren ätherischen Lösung nach sanftem Schütteln auftreten. In dieser Lösung sind die Streifen, wie ich finde, auch bei Anwendung reinen Hömoglobins oder sauerstoffhaltigen Cyanwasserstoffhämoglobins sehr deutlich.

Hämoglobin in Essigsäure gelöst wird durch überschüssiges 
Ammon vollständig gefällt, wenn man durch Erwärmen eben den Ueberschuss des Ammons austreibt (C. Schmidt).

A meisensäure (Säureband 41-50), But tersäure (Säureband 43-50), Propionsäure, Milchsäure, Citronensäure, Weinsäure, Apfelsäure verhalten sich der Essigsäure sehr ähnlich und geben sämmtlich ein Säureband.

\section{Monochloressigsäure.}

Während man aus reinem Hämoglobin mit Essigsäure und Chloriden Häminkrystalle darstellen kann, ist es mir nicht gelungen, solche durch Behandeln von Hämoglobin mit Monochloressigsäure zu erhalten. Spuren der Säure wirken schon in der Kälte zersetzend, die Farbe wird braun, die Sauerstoffstreifen verschwinden, es tritt ein Säureband, identisch mit dem der Essigsäure auf, welches beim Kochen nicht 'verändert wird, die Lösung bleibt klar.

\section{Valeriansäure.}

Bringt man sehr wenig Valeriansäure $\mathrm{zu}$ concentrirten Hämoglobinlösungen, so verhält sich alles so wie es bei der Oxalsäure lautet. Säureband 44-49.

Wenn man aber zu einigen Cubiccentimetern der rothen Lösung mehrere Tropfen Valeriansäure bringt, so bleiben sie als eine klare farblose Schicht und scharf abgegrenzt über der Lösung. Beim Schütteln erhält man eine undurchsichtige bräunlich weisse Masse. Nach mehreren Stunden ruhigen Stehens an der Luft bei etwa $10^{\circ} \mathrm{C}$. sammelt sich die Säure, oder der grösste Theil derselben, wieder oben an, jetzt ist sie aber dunkelbraunroth gefärbt und zeigt ein Säureband. Die untere Schicht ist fast ganz farblos, aber undurchsichtig. Sie wird jedoch beim Erwärmen wasserklar. Beim Kochen tritt eine Vermengung der Schichten ohne Gerinnung ein, beim $\mathbf{A b}$ kühlen trennen sich die Schichten wieder u. s. f.

\section{Kohlensäure.}

Leitet man einen lebhaften Kohlensäurestrom anhaltend in der Kälte durch eine wässerige Sauerstoffhämoglobinlösung, so tritt nicht die geringste Trübung ein, die Lösung erhält nur einen schwachen violetten Schimmer. Im Spectrum sieht man, wie die beiden Sauerstoffstreifen allmählich mit einander verschmelzen, weil der Streifen des reducirten Hämoglobins auftritt. Dieser bleibt zuletzt übrig, 
kann aber durch Schütteln mit Luft wieder in die beiden Sauerstoffstreifen umgewandelt werden. Der violette Schimmer verschwindet daun. Lösungen von Blutkrystallen in kohlensaurem Wasser unterscheiden sich von rein wässerigen Lösungen namentlich dadurch, dass sie sich mit Bleiessig, Kalkwasser, Barytwasser trüben, während umgekehrt mit wenig Aetzbaryt erwärmte Hämoglobinlösungen durch Kohlensäure nicht getrübt werden. Lässt man die kohlensaure Hämoglobinlösung, welche nur den Streifen des reducirten Hämoglobins zeigt, einige Stunden in der Kälte an der Luft stehen, ohne zu schütteln, so verwandelt sich der Streifen von oben nach unten vorwärts schreitend in die Sauerstofisstreifen, gleichzeitig tritt aber das Methämoglobinband auf (47-53 Taf. IX, Fig. 16). Beim Erwärmen verschwindet dieses Absorptionsband und kommt beim Abkühlen nicht wieder zum Vorschein. Bei weiterer Temperatursteigerung tritt Gerinnung ein. Es ist noch nicht nachgewiesen, $a b$ beim Durchleiten von Kohlensäuregas durch eine Blut- oder Sauerstoffhämoglobinlösung der Sauerstoff $\mathrm{s}$ ä $\mathrm{mmtlich}$ ausgetrieben oder ob nicht selbst bei niedriger Temperatur ein Theil verzehrt wird. Ich muss, wie Pflüger, letzteres für wahrscheinlich halten. Denn erstlich ist die Kohlensäure eine Säure, welche nicht einmal zu den schwächsten Säuren gezählt werden kann; sie röthet Lacmus, treibt Harnsäure aus Uraten aus, wird von Blausäure aus Carbonaten nicht ausgetrieben. Die Kohlensäure kann also gerade wie andere Säuren zerstörend auf reines Hämoglobin einwirken. Man braucht nun in der That nur durch concentrirte Lösungen auch bei niedriger Temperatur ( 9 bis $12^{\circ} \mathrm{C}$.) einen lebhaften Kohlensäurestrom zu leiten, so tritt nach sehr kurzer Zeit eine Verdunkelung der Farbe ein, die nicht blos auf das Auftreten sauerstofffreien Hämoglobins zurückgeführt werden kann, denn auch bei anhaltendem Behandeln der Lösung mit atmosphärischem Sauerstoff wird diese nicht mehr gánz so hellroth, wie sie vorher war. Es rührt dieses her von dem Vorhandensein eines neuen Farbstoffes in der kohlensauren Lösung, denn man kann in dicken Schichten derselben eine Absorption gerade da bemerken, wo unzersetztes Hämoglobin keine Absorption zeigt (zwischen 45 und 50). Es geht hieraus hervor, dass die Kohlensäure wie andere Säuren das Hämoglobin auch in der Kälte zersetzt, wenn sie in genügender Menge einwirkt. Zweitens ist schon vor mehr als zehn Jahren von Lothar Meyer nachgewiesen worden, dass ein Zusatz von Weinsäure zu Blut das Entweichen des Sauerstoffs aus diesem in 
eine Luftleere verhindert. Wir müssen daraus schliessen, dass der mit dem Hämoglobin locker verbundene Sauerstoff zu Oxydationen verwendet wird, sowie die Säure dazu tritt. Nun aber sehen wir an dem Schwinden der Sauerstoffbänder im Spectrum ohne jede Sauerstoffgasentwickelung und an der Gleichheit des Säurebandes bei Blut- und Hämoglobinlösungen, dass diese Oxydationsprocesse auch in einer reinen Sauerstoffhämoglobinlösung stattfinden, sowie eine Säure dazu kommt, auf Kosten natürlich des Hämoglobins selbst. Ja es ist damit der Verbrauch sämmtlichen Hämoglobinsauerstoffes in der Kälte ror sich gehe, gar nicht einmal nöthig, wie wir unten sehen werden, dass eine Säure oder Sauerstoff von aussen hinzutritt. Es ist aber das Hinzukommen einer Säure, und sei es auch nur Kohlensäure, jedenfalls der Sauerstoffzehrıng förderlich. Aus diesen Gründen ist die Ansicht die wahrscheinlichere, dass beim Durchleiten von Kohlensäure durch Sauerstoffhämoglobinlösungen nicht sämmtlicher Sauerstoff ausgetrieben, sondern ein Theil verbraucht wird zur Bildung von Zersetzungsproducten. Diese treten, wie der Versuch mir gezeigt hat, bei Kohlensäuredurchleitung auf, noch ehe sämmtliches Hämoglobin in der Lösung sauerstofffrei geworden ist. Man kann daher Sauerstoffhämoglobin auch in der Kälte durch Kohlensäure gar nicht ohne theilweise Oxydation sauerstoffrei machen. Noch viel schneller zersetzend als auf Sauerstoffhämoglobin wirkt aber, wie Pflüger fand, die Kohlensäure auf das reducirte Blutroth, wenn es rein in wässeriger Lösung sich befindet (dieses Archiv I, S. 78).

Eine ganz andere Frage ist es offenbar, ob trotz dieser zersetzenden Eigenschaft des Kohlensäuregases nicht das Hämoglobin die Fähigkeit besitzt, vor der Zersetzung sich locker oder fest mit Kohlensäure zu verbinden. Obwohl dies nach den vorstehenden Bemerkungen nicht gerade wahrscheinlich war, so habe ich doch einige Versuche darüber anzustellen für zweckmässig erachtet.

Die Versuche lieferten das Ergebniss, dass absolut reine wässerige Sauerstoffhämoglobinlösungen etwas weniger Kohlensäure absorbiren, als reines Wasser unter deuselben Bedingungen.

Durch eine 0,8 procentige Lösung von Sauerstoffhämoglobin vom Hunde wurde ein sehr lebhafter Strom gehörig gewaschener Kohlensäure anfangs bei $11,5^{\circ}$, während der letzten halben Stunde bei genau $11,0^{\circ}$, geleitet. Die Lösung blieb vollkommen klar (nur der Schaum ist sehr zähe), wurde aber sehr dunkel und es trat 
der Streifen des sauerstofffreien Hämoglobins auf; in dicken Schichten, war jedoch nach dreistündigem Durchleiten des Gases gleichzeitig eine Absorption im Roth eben wahrnehmbar. Nun wurden $34,0 \mathrm{Cc}$. der Lösung zuerst bei $13^{\circ} \mathrm{C}$, dann in der Handwärme entgast. Beim Erwärmen auf $40^{\circ}$ erhielt ich kein Gas mehr, ebenso lieferte die Lösung nach Zusatz von verdünnter Phosphorsäure keine Spur durch Kali absorbirbaren Gases. Die erhaltene Gesammtgasmenge betrug $29,84 \mathrm{Cc}$. (bei $0^{0}$ und $1 \mathrm{M}$.), hiervon ist aber $0,5 \mathrm{Cu}$ biccentimeter Gas abzuziehen, welches von Kali nicht absorbirt wurde (Luft), bleiben 29,3. Nun absorbiren 34,0 Cc. Wasser bei 11, $0^{\circ}$ nach Bunsen 29,50 Cc. Kohlensäure (bei $0^{0}$ und $1 \mathrm{M}$.), also etwas mehr als die Hämoglobinlösung.

Beim zweiten Versuch wurden 50,0 Cc. einer Lösung, die 1,2 Proc. Sauerstoffhämoglobin enthielt, entgast, nachdem Kohlensäure während der letzten halben Stunde bei $12,1^{\circ}$, drei Stunden lang ohne Unterbrechung in lebhaftem Strom durchgeleitet worden war. Auch hier entwich die Kohlensäure vollständig vor der Erwärmung auf $40^{\circ}$ und Phosphorsäurezusatz lieferte nicht eine Spur durch Kali absorbirbaren Gases. Im Ganzen wurden absorbirt 41,10 Cc. Kohlensäure (gemessen bei $0^{0}$ und 1 M.). Es absorbiren aber nach Bunsen $50,0 \mathrm{Cc}$. Wasser bei $12,1^{\circ} \mathrm{C}$. mehr, nämlich $41,85 \mathrm{Cc}$. Kohlensäure (bei $0^{0}$ u. $1 \mathrm{M}$. gem.). Somit glaube ich behaupten zu dürfen, dass Hämoglobin sich mit Kohlensäure nicht chemisch verbindet und eher wie andere Säuren und Salze die Absorptionsfähigkeit des Wassers für Kohlensäure ein wenig vermindert. Ich habe es nicht für nöthig erachtet, nach diesen Ergebnissen feinere Absorptionsversuche mit Kohlensäure und Hämoglobinlösungen anzustellen. halte es aber nach den Versuchen von Zuntz für wahrscheinlich, dass die Verbindung, in der das Hämoglobin in den circulirenden Blutkörpern existirt, ein hohes Absorptionsvermögen für Kohlensäure hat.

\section{Bernsteinsäure.}

In der Kälte ohne Trübung, Farben-, Spectrum-Aenderung mit Hämoglobinlösung mischbar. Beim Erwärmen verschwinden die Sauerstoffhämoglobinstreifen, die Lösung wird braun. Es erscheint eị Säureband $(45-50)$. 


\section{Carbolsäure.}

Eine kalte wässerige Carbolsäurelösung zu einer Hämoglobinlösung gebracht ruft darin eine Trübung, grössere Mengen einen rothen Niederschlag hervor. Die Sauerstoffhämoglobinstreifen verschwinden sofort. Ein Säureband habe ich nicht bemerkt. Die hämoglobinrothen Flocken haften dem Glase sehr fest an. Die übrige Flüssigkeit bleibt milchig getrübt. Die Flocken sind in Eisessig leicht löslich und geben damit eine braune Lösung mit dem Säureband $46-52$.

\section{Benzoesäure.}

Kalte wässerige Benzoesäurelösungen verändern weder die Farbe noch das Spectrum einer Hämoglobinlösung und bewirken keine Trübung. Bringt man Krystalle der Säure in die rothe Flüssigkeit, so wird sie beim Erwärmen braun, die Krystalle lösen sich, die Streifen im Spectrum verschwinden, es tritt ein Säureband auf. Die Lösung bleibt beim Kochen klar.

\section{Gallussäure.}

Bringt man reichliche Mengen fester Gallusșäurekrystalle in der Kälte in wässerige Hämoglobinlösungen, so verändern diese ihre Farbe nicht, im Spectrum sieht man nach wie vor die Hämoglobinstreifen, die Lösungen bleiben klar, nachdem sich die Gallussäure abgesetzt hat. Lässt man sie aber nur 1 bis 2 Stunden bei 8 bis $10^{\circ} \mathrm{C}$. an der Luft stehen, so werden sie braun, die Sauerstoffstreifen im Spectrum werden immer schwächer und schwinden ganz. Zugleich tritt ein Säureband $(44-51)$ auf. Beim Kochen bleiben die gallussauren Lösungen klar.

Man kann die beschriebenen Veränderungen ohne Coagulation sofort hervorrufen, wenn man die Hämoglobinlösungen, welche Gallussäure enthalten, erwärmt.

\section{Pyrogallussäure.}

Bringt man Pyrogallussäurekrystalle in Hämoglobinlösungen, so lösen sie sich darin leicht und ohne Trübung auf, aber die Lösung wird braun und die Hämoglobinstreifen verschwinden allmäh- 
lich. Es tritt ein ziemlich schmaler Absorptionstreifen auf, welcher dieselbe Lage wie der des Methämoglobins hat. Beim Erwärmen gerinnen die pyrogallussauren Lösungen, auch wenn vor dem Beginne des Erwärmens die Sauerstoffhämoglobinstreifen verschwunden waren.

\section{Harnsäure.}

Wenn man reichlich reinste feste schneeweisse Harnsäure in eine Hämoglobinlösung einträgt, so verändert sich die Losung in der Kälte nicht bei mehrstündigem Stehen an der Luft $\left(8^{\circ}\right)$, die Harnsäure setzt sich farblos ab, die Flüssigkeit und ihr Spectrum bleiben wie vorher. Lässt man aber einen Tag lang stehen oder erwärmt man ganz gelinde, so schwinden die Sauerstoffhämoglobinstreifen, die Lösung wird röthlichbraun und es erscheint ein Absorptionstreifen im Roth. Beim Sieden tritt keine Gerinnung ein. Die Harnsäure setzt sich bein Abkühlen kaum bräunlich gefärbt: zu Boden. Die Flüssigkeit bleibt klar. Ein Theil Harnsäure braucht 14- bis 15 tausend Theile Wasser von $20^{\circ} \mathrm{C}$., um sich zu lösen. Man sieht hieraus, wie wenig Harnsäure zur Zersetzung des Hämoglobins erforderlich ist.

\section{Hippursäure.}

Bringt man einige Hippursäurekrystalle in eine Hämoglobinlösung, so verändert sie nach kurzer Zeit auch in der Kälte ihre Farbe. Sie wird braunroth, die Hämoglobinstreifen verschwinden und es tritt ein Säureband auf. Die Lösung bleibt beim Sieden ohne weitere Veränderung der Farbe nnd des Spectrums klar. Wie wenig Hippursäure zur Zersetzung des Hämoglobins erforderlich ist, ergibt sich aus ihrer geringen Löslichkeit in kaltem Wasser (etwa 1/6 Proc. bei $0^{0}$ ).

\section{Cy anwasserstoffs äure.}

Das merkwürdige Verhalten des Hämoglobins zum Cyauwasserstoff habe ich bereits in meiner Schrift „Die Blausäure physiologisch untersucht" 1868 , S. $82,83,85$ bis 91 beschrieben und vervollständige hier die dortigen Mittheilungen durch Abbildung der zwei neuen Spectra. Fig. 12 stellt den Absorptionstreifen des sauerstoffhaltigen, Fig. 14 die beiden Absorptionsbänder des reducirten Cyan- 
wasserst offhämoglobins dar, welche nach Schütteln der Lösung mit Luft in das verwaschene Absorptionsband (Fig. 12) übergehen.

Vergleichen wir nun die Wirkungen der verschiedenen Säuren untereinander, so ergiebt sich, dass zu einer wässerigen Hämoglobinlösung keine der genannten Säuren (auch Blausäure nicht im Ueberschuss) hinzugefügt werden kann, ohne dass selbst bei niedriger Temperatur -- etwa $+10^{\circ} \mathrm{C}$ - Zersetzung eintritt. Die meisten Säuren bewirken die`Zersetzung ohne Erwärmung sofort, einige erst nach mehreren Stunden. Diejenigen, welche nicht sogleich das Hämoglobin zerstören, sind die schwächsten oder die am schwersten löslichen von den hier aufgezählten Säuren, nämlich Borsäure, Kohlensäure, Bernsteinsäure, Benzoesäure, Gallussäure, Harnsäure, Hippursäure, Blausäure. Aber auch diese Agentien bewirken, wenn sie in genügender Menge einer Blutfarbstofflösung zugesetzt werden, bei gelindein Erwärmen sehr schnell Zersetzung. Es giebt sich die Zersetzung in den meisten Fällen durch eine Farbenänderung der rothen Flüssigkeit zu erkennen. Die hellblutrothe Farbe geht in Braun oder Dunkelroth über, ohne dass in irgend einem der beobachteten Fälle deutlicher Dichroismus zur Wahrnehmung gelangte. Gleichzeitig mit dem Farbenwechsel tritt in allen Fällen eine Aenderung des Spectrums ein. Die beiden Absorptionstreifen des unzersetzten Sauerstoffhämoglobins verschwinden und es tritt zwischen $\mathrm{B}$ und $\mathrm{D}$, meistens aber zwischen $\mathrm{C}$ und $\mathrm{C}^{1} / 2$ D ein Absorptionstreifen, ein Säureband auf, dessen Lage nicht bei allen Säuren dieselbe, aber auch nicht bei allen verschieden ist. Bei den schwächsten Säuren gehört der Absorptionstreifen dem Methämoglobin allein an, so z. B. bei der Borsäure und Kohlensäure, und wahrscheinlich auch der Pyrogallussäure. Die Borsäure aber hat im Ueberschuss in der Wärme zugesetzt auch ein besonderes Borsäureband zur Folge. Die Säurebänder kommen nur dann zur Beobachtung, wenn die zugesetzte Säure keine Fällung bewirkte. Mit Rücksicht auf die Fällbarkeit des Hämoglobins sind die genannten Säuren in vier Gruppen zu sondern. Die Säuren der 1. Gruppe bewirken weder in kleinen noch ingrossen Mengen zugesetzt, weder in der Kälte, noch beim Erhitzen eine Fällung, sondern pur Farbenänderùng, hierher gehören die gewöhnliche 
Phosphorsäure, die phosphorige Säure, die schwefelige Säure, die Oxalsäure, Fssigsäure, Ameisensäure, Buttersäure, Propionsäure. Milchsäure, Citronensäure, Weinsäure, Aepfelsäure, Monochloressigsäure, Bernsteinsäure, Benzoesäure, Gallussäure, Harnsäure, Hippursäure. Alle diese Säuren haben das Auftreten beim Erwärmen unverändert bleibender Säurebänder zur Folge mit Auslöschung der Sauerstoffstreifen. Die Säuren der 2. Gruppe bewirken in kleinen und in grösseren Mengen sowohl in der Kälte wie in der Wärme im Ueberschuss der Säure unlösliche Fällungen mit Zersetzung, so Metaphosphorsäure, Phosphormolybdänsäure (?), Carbolsäure. Die Säuren der 3. Gruppe bewirken in sehr kleinen Mengen oder in starker Verdunnung in der Kälte keine Fällung, sondern nur sofortige Farbenänderung, in grösseren Mengen dagegen im Ueberschuss des Fällungsmittels beim Erwärmen lösliche Niederschläge, so die Salzsäure, Salpetersäure, Schwefelsäure, Chromsäure. Die Säuren der 4. Gruppe, zu welcher die schwächeren Säuren gehören, die Pyrogallussäure und Kohlensäure, bewirken in der Kälte anch im Ueberschuss keine Fäll ungen, und solche Lösungen coaguliren beim Erwärmen, auch nachdem sie schon vorher durch die Säuren verändert worden. Bei der Kohlensäure ist Methämoglobinbildung festgestellt. Da aber aus Hämoglobin niemals Methämoglobin wird ohne gleichzeitige Globinbildung, so muss ich glauben, dass bei meinen Versuchen das Globin in dem äusserst zähen Schaum verblieb. Ein eigenthümliches Verhalten zeigen, wie erwähnt wurde, die Borsäure und Valeriansäure.

Jetzt schon das verschiedene Verhalten der Säuren zum Hämoglobin erklären wollen, scheint nicht wohl möglich. Soviel geht nur mit Wahrscheinlichkeit aus den angeführten Beobachtungen hervor, dass bei jeder durch eine Säure bewirkten Zersetzung des Blutroths eine Spaltung desselben in Eiweiss und einen eisenhaltigen Farbstoff eintritt. Dieser letztere ist entweder selbst wieder eiweissartiger Natur, nämlich Methämoglobin, oder nicht, nämlich Hämatin. Im ersteren Falle coagulirt die init Säure zersetzte Lösung beim Erwärmen, im letzteren ist entweder ein Niederschlag schon in der Kälte entstanden, der aus Eiweissflocken mit mechanisch anhaftendem Hämatin besteht, oder es tritt überhanpt keine Fällung, auch beim Frwärmen nicht, ein; dann sind vermuthlich die abgespaltenen 
Albumine durch die Säuren in Syntonin verwandelt und das Hämatin gleichfalls in der sauren Lösung gelöst.

Ueber die Einwirkung der Alkalien und einiger alkalisch reagirender Lösungen auf Sauerstoffhämoglobin.

Kaliumhydrat.

Sehr verdünnte Kalilauge wirkt nicht zersetzend auf reines Sauerstoffhämoglobin in Wasser in der Kälte. Beim Erwärmen wird aber die Lösung schnell dunkelroth und im Spectrum bemerkt man eine stärkere Absorption des Roth. Die Lösung gerinnt nicht mehr beim Erhitzen, hellt sich dabei bedeutend auf und wird dichromatisch, in dünnen Schichten moosgrün, in dicken röthlichbraun. Nach dem Sieden tritt ein verwaschener, breiter, nicht intensiver Absorptionstreif (von 50--60) auf. Concentrirte Kalilauge ruft schon in minimalen Mengen in der Kälte die beschriebenen Veränderungen sofort hervor. Meerschweinchenblutkrystalle sind nach Lehmann in concentrirter Kalilauge unlöslich. Die lichtrothe Farbe ihrer wässerigen Lösung wird durch Kali in ein schmutziges Gelb verwandelt.

\section{Natriumhydrat}

verhält sich ganz ähnlich wie Kali, nur werden die Lösungen ceteris paribus beim Kochen mehr grün, auch in dicken Schichten grünlichbraun. Die Hämoglobinstreifen verschwinden nicht ganz so schnell wie nach Kalizusatz. Absorption : 50-58.

Ammoniak.

Ammoniakwasser wirkt auf Hämoglobin durchweg ganz ähnlich wie Kali- oder Natronlauge, nur langsamer. C. Schmidt fand, dass die mit Ammon versetzten Hämoglobinlösungen mit Essigsäure einen im Säureüberschuss schwer löslichen Niederschlag geber. Ich finde diesen Niederschlag inı Säureüberschuss leicht löslich. Nach Lehmann sind die Blutkrystalle des Meerschweinchens sehr leicht löslich in Ammoniakwasser und tritt die Fällung aus der alkalischen Lösung durch Essigsäure vor dem Schwinden der alkalischen Reaction ein. Höchst verdünntes Ammoniakwasser ist ein ausgezeichnetes Lösungsmittel für Hämoglobin.

\section{Baryumhydrat.}

Reine Hämoglobinlösungen werden weder von concentrirtem noch verdünntem Barytwasser getrübt. Die Farbe und das Spectrum 
bleiben in der Kälte unverändert. Bei gelindem Erwärmen schwinden die Hämoglobinstreifen ziemlich schnell, die Lösung wird grünlich gelb, bei weiterem Erwärmen gelblich grün, dann ganz grün und nur in sehr dicken Schichten oder bei sehr gesteigerter Concentration erscheint sie röthlichbraun: die Flüssigkeit ist sehr stark dichroitisch. Beim Kochen schäumt das Flüssigkeitsgemisch stark, bleibt aber vollkommen klar und grür. Beim Stehen an der Luft trübt sich die Lösung nur dann, wenn Baryt im Ueberschuss vorhanden war durch Bildung von Baryumcarbonat. Man kann durch eine Lösung; die keinen ü be r schüssig en Baryt enthält, stundenlang Kohlensäure leiten, ohne die geringste Trübung zu erhalten. C. Schmidt fand, dass die aus der grünen Lösung auf Essigsäurezusatz sich ausscheidenden Flocken sich im Säureüberschuss schwerer lösen, als die aus Kali oder Natronlösung, leichter als die aus Ammonlösung gefällten.

\section{Caleiumhydrat.}

Alles wie beim Barytwasser. Nur ist die grüne Farbe der Lösung nach dem Kochen heller.

Wenn man Kalkwasser, ohne zu erwärmen, mit einer reinen sauerstoffhaltigen Cyanwasserstoffhämoglobinlösung mischt, so sieht man nach ganz kurzer Zeit das breite verwaschene Absorptionsband (Fig. 12) schwinden und die Sauerstofthämoglobinstreifen wieder erscheinen.

\section{Kaliumcarbonat.}

Das Verhalten dieses Körpers zu Hämoglobin ist höchst eigenthümlich. Reichliche Mengen kalter concentrirter wässeriger Kaliumcarbonatlösung sind ohne Trübung, ohne Veränderung der Farbe und des Spectrums mit Sauerstofthämoglobinlösungen mischbar und die Lösungen gerinnen in der Hitze, wie die wässerigen Lösungen unter Entfärbung und Ausscheidung eines flockigen Coagulums. Wenn man aber verdünnte Kaliumcarbonatlösungen anwendet, dann wird zwar anfangs auch nichts im optischen Verhalten der Blutrothlösung verändert, in der Wärme aber gerinnt sie nicht mehr, sie wird braun und bleibt vollkommen klar beim Kochen.

Bringt man festes Kaliumcarbonat in sehr grossen Quantitäten in concentrirte Hämoglobinlösung, so löst es sich leicht darin auf und verdrängt gewissermassen, wie Hoppe-Seyler zuerst bemerkte, das Hämoglobin aus der Lösung und zwar, wie es scheint, ohne es im Mindesten zu zersetzen. Das anfangs gleichmässig rothe Ge- 
misch theilt sich in zwei Schichten, eine durchsichtige vollkommen farblose ganz flüssige untere: Kaliumcarbonat, und eine rothe undurchsichtige obere, welche wahrscheinlich aus einer amorph ausgefäliten Verbindung des Hämoglobin mit Kali besteht. In feiner Vertheilung sind die Sauerstoffstreifen und nur sie noch nach Tagen $\left(7-10^{\circ}\right.$ C. $)$ bei dieser Schicht sichtbar. Man mag noch so oft das Gemisch schütteln, immer sondert es sich wieder in die 2 Schichten.

\section{Kaliumbicarbonat.}

Kalte concentrirte Lösungen bewirken keine Trübung oder Farbenveränderung. Beim Erwärmen gerinnen die Lösungen mit Kohlensäureentwickelung, beim Kochen aber löst sich das Gerinnsel klar auf. Erwärmt man Hämoglobin mit sehr verdünnten Kaliumbicarbonatlösungen, dann tritt keine Trübung ein, die Lösung wird braun, bleibt aber klar.

\section{Natriumcarbonat.}

Kalte Sodalösungen jeder Concentration besitzen ein ausgezeichnetes Lösungsvermögen für Blutkrystalle und solche Lösungen halten sich, wie schon bemerkt wurde, länger unzersetzt als wässerige. In ihrem optischen Verhalten weichen sie nicht im Mindesten davon ab. Aber beim Erwärmen zersetzen sie sich, ohne dass Gerimnung eintritt. Wendet man Sauerstoffhämoglobin vom Hunde an, so tritt die Zersetzung bei sehr verschiedener Concentration der Lösung doch stets plötzlich bei genau $54^{\circ}$ C. ein. (S. oben S. 402.) Nur mit einem enormen Ueberschuss von Soda versetzte Blutrothlösungen gerinnen in der Wärme. Das braune flockige Coagulum bleibt dann beim Kochen, wie es scheint, ungelöst.

\section{Natriumbicarbonat}

verhält sich so, wie es beim Natriumcarbonat angegeben wurde. Erwärmt man eine wässerige Blutrothlösung mit einem sehr grossen Ueberschusse von Natriumbicarbonat, dann tritt Gerinnung und enorme Kohlensäureentwickelung ein und das Gerinnsel löst sich nicht bei anhaltendem Kochen.

\section{Ammoniumcarbonat, Ammoniumbicarbonat}

sind ohne Trübung oder Aenderung des optischen Verhaltens mit Hämoglobinlösungen mischbar. Die Lösungen gerinnen beim Erwärmen_trotz der alkalischen Reaction mit stürmischer Kohlensäureentwickelung und die flockigen Gerinnsel bleiben auch bei anhaltendem. Kochen ungelöst. 


\section{Natriumphosphat. \\ $\left(\mathrm{Na}_{2} \mathrm{HPhO}_{4}\right.$ in Wasser.)}

Eine alkalisch reagirende kalt gesättigte Natriumphosphatlösung ist mit einer Hämoglobinlösung ohne Veränderung des optischen Verhaltens, ohne Trübung mischbar. Bei Erwärmen coagulirt die Lösung trotz der alkalischen Reaction. Nach 4 bis 5tägigem Stehen $\left(8-10^{\circ}\right)$ einer Lösung von Blutkrystallen in einer Natriumphosphatlösung tritt ein Absorptionstreifen im Roth auf von 44-52.

\section{Ammoniumphosphat}

verhält sich wie Natriumphosphat.

\section{Natriumborat.}

Reines Sauerstoffhämoglobin in Wasser gelöst zeigt mit kalter concentrirter Boraxlösung versetzt keine Veränderung der Farbe, der Absorptionstreifen, und keine Trübung. Beim Erwärmen verschwinden die Sauerstoffstreifen allmählich und die Lösung wird braun. Sie zeigt in dicken Schichten einen Streifen von 47-52 wie das Methämoglobin (Taf. IX. Fig. 16), aber schwach; im Uebrigen ist das Spectrum schattig von 39-59 und sonst schwarz. Die Lösung bleibt zwar beim Kochen vollständig klar, sie trübt sich aber beim Abkühlen, die Trübung verschwindet bei erneutem Kochen, kommt wieder beim Abkühlen u. s. f. In Boraxlösung gelöste Blutkrystalle mit einem sehr grossen Ueberschuss von Boraxkrystallen versetzt coaguliren beim Erwärmen. Es findet offenbar eine Verdrängung des Hämoglobins aus der Lösung statt. Das Hämoglobin ist in der (schwach alkalisch reagirenden) verdünnten wässerigen Boraxlösung leichter löslich, als in Wasser.

\section{Kalinmcyanid.}

Das eigenthümliche Verhalten des Hämoglobins zu Cyankalium habe jch in meiner Schrift "Die Blausäure physiol. unters. " Bonn 1868, S. $81-83,85-91,96-97,105-106$ beschrieben, wo ich auch darauf aufmerksam machte, dass durch Einwirkung des Cyankalium auf Hämatin dasselbe Spectrum erhalten wird, wie durch Behandeln des Sauerstoffhämoglobins mit Cyankalium oder Blausäure (Fig. 12). Reducirende Mittel geben dann in allen drei Fällen das in Fig. 14 abgebildete Spectrum, welches sofort entsteht, wenn Cyankalium unter Luftabschlu.ss auf sauerstofffreies Hämoglobin wirkt. 
Vergleicht man die Wirkungen der Alkalien und alkalischen Salzlösungen auf Hämoglobin untereinander, so ergiebt sich eine sehr viel grössere Uebereinstimmung aller als bei den. Säuren. In sämmtlichen genannten Lösungen, wenn sie nicht $\mathrm{zu}$ concentrirt sind, ist das Sauerstoffhämoglobin in der Kälte leicht löslich ohne Farbenänderung, ohne Veränderung des Spectrum. Sind die Lösungen concentrirt oder werden die verdünnteren erwärmit, so tritt in allen Fällen Farbenänderung ein, die blutrothe Farbe geht in Braun über, die Lösung ist aber in dünnen Schichten grün, sie ist dichromatisch, und zwar geht die zersetzende Wirkung der Aetzalkalien dabei parallel ihrer Basicität. Am schnellsten zerstört Kali, dann Natron, Ammoniak, Baryt, Kalk. Im Spectrum sind dann die beiden Hämoglobinstreifen ausgelöscht und statt dessen eine verwaschene Absorption im Roth und Orange sichtbar: das Spectrum des Hämatinalkali. Beim weiteren Erhitzen der mit Aetzalkalien versetzten Hämoglobinlösungen tritt keine Coagulation ein, die Lösung bleibt beim Sieden klar. Man kann jedoch eine Gerinnung auch in alkalischen Lösungen bewirken, durch Zusatz sehr bedeutender Mengen eines beliebigen Alkalicarbonates - am besten Kaliumcarbonat, am schwierigsten Natriumcarbonat - oder Alkalibicarbonates.

Auch in den alkalisch reagirenden Lösungen neutraler Alkaliphosphate coagulirt das Hämoglobin.

Ein besonderes Verhalten zeigten Borax und Cyankalium.

Das Verhalten des Blutfarbstoffs in alkalischen Lösungen bietet der Erklärung weniger Schwierigkeiten als das in sauren. Da das Sauerstoffhämoglobin eine Säure ist, so erklärt sich seine leichte Löslichkeit in verdünnten Alkalien durch die Annahme chemischer Bindung; es würde Kaliumhämoglobinat, Baryumhämoglobinat u. s. w. entstehen. Dass bei der Zersetzung in warmen Aetzalkalilaugen keine Gerinnung eintritt, wäre durch Bindung des bei einer gewissen Temperatur (beim Natron wie wir sahen $54^{\circ}$ ) sich abspaltenden Albumins, durch das freie Alkali und die Bildung von dichromatischem Hämatinalkali begreiflich, indem sowohl die Alkalialbuminate als das Hämatinalkali in Wasser löslich sind. Die Gerinnung dagegen in solchen Lösungen, welche einen enormen Ueberschuss von gelöstem Alkalicarbonat oder Bicarbonat enthalten, könnte man sich vielleicht durch eine Zerlegung der Albuminate durch dieh eftig sich entwickelnde Kohlensäure oder durch einfache Verdrängung derselben erklären, 
was aber noch zu begründen wäre. Im letzteren Falle wäre die Erscheinung analog der amorphen Ausscheidung des Kaliumhämoglobinates (?) in höchst concentrirten Lösungen von Kaliumcarbonat in der Kälte, wo wahrscheinlich eine einfache Verdrängung des weniger löslichen Körpers ohne vorherige Zersetzung stattfindet.

Einwirkung einjger Salze auf das Hämoglobin.

In concentrirten und verdünnten wässerigen Sauerstoffhämoglobinlösungen vom Hunde bewirken nach meinen Untersuchungen keine Trübung, keinen Niederschlag und - abgesehen von der Verdünnung - keine Aenderung der Absorptionstreifen im Spectrum kalte concentrirte und verdünnte wässerige Lösungen von

$\begin{array}{lll}\text { Kaliumnitrat, } & \text { Natriumchlorid, : } & \text { Calciumchlorid, } \\ \text { Kaliumsulphat, } & \text { Natriumhyposulphit, Magnesiumchlorid, } \\ \text { Kaliumchlorat, } & \text { Natriumnitroprussid, Magnesiumsulphat, } \\ \text { Kaliumchlorid, } & \text { Ammoniumchlorid, } & \text { Kobaltnitrat, } \\ \text { Kaliumchromat, } & \text { Ammoniumsulphat, } & \text { Nickelnitrat, } \\ \text { Kaliumbichromat, } & \text { Ammoniumnitrat, } & \text { Zinksulphat, } \\ \text { Kaliumferrocyanid, } & \text { Ammoniumoxalat, } & \text { Cadmiumnitrat, } \\ \text { Lithiumchlorid, } & \text { Ammoniumacetat, } & \text { Kalium natrium tartrat. } \\ \text { Natriumnitrat, } & \text { Baryumnitrat, } & \\ \text { Natriumsulphat, } & \text { Baryumchlorid, } \\ & \\ \text { Das Verhalten aller dieser Salze in Sauerstoffhämoglobinlösun- }\end{array}$
gen ist in der Kälte gleich indifferent. Andere Farbenänderungen, als die durch Verdünnung bedingte, werden nur bei den an und für sich farbigen Lösungen beobachtet, Kaliumbichromat, Kaliumchromat, Kaliumferrocyanid, Nitroprussidnatrium, Kobaltnitrat, Nickelnitrat. Auch weun man die Lösungsgemische erwärmt, zeigen sie alle das gleiche Verhalten: Coagulation. Beim gelinden Erwärmen werden die Sauerstoffhämoglobinstreifen allmählich schwächer. Einige Secunden vor dem Augenblick, da sie gänzlich verschwinden, beginnt die Gerinnung; die Lösung entfärbt sich, wofern farblose Salze angewandt werden, sonst nimmt sie die Farbe der Salzlösung an und braune, beim Sieden stark schrumpfende Flocken schwimmen in ihr. Das Gerinnsel ist leicht löslich in Eisessig. Die essigsaure Lösung ist braun und zeigt ein Säureband.

Wahrscheinlich in allen genannten Lösungen - ich stellte den Versuch nur mit Kaliumferrocyanid und Kaliumchromat an - ent- 
steht in der Kälte durch Eisessig ein eiweissartiger im Ueberschuss der Essigsäure leicht löslicher Niederschlag.

Es giebt nun noch eine ganze Reihe von Salzen, welche dem Hämoglobin gegenüber sich anders verhalten, als die eben aufgezählten. Einigen von diesen wenden wir uns jetzt zu.

\section{Zinklactat.}

Die kalte wässerige sauer reagirende Lösung erzeugt in verdünnten und concentrirten Hämoglobinlösungen keine optische Veränderung. Bei gelindem Erwärmen aber schwinden schnell die Sauerstoffstreifen im Spectrum. Die Flüssigkeit wird braun und bleibt beim Kochen klar. Es ist bemerkenswerth, dass Zinklactatlösungen trotz ihrer sauren Reaction nicht zersetzend schon in der Kälte wirken.

\section{Mercurinitrat.}

Frisch bereitete kalte stark sauer reagirende wässerige Quecksilbernitratlösungen sind ohne Trübung mit Hämoglobinlösungen mischbar. Die Farbe ändert sich indess sehr schnell, sie wird röthlich braun und neben den schnell verschwindenden Hämoglobinstreifen bemerkt man ein Absorptionsband (48-52). Beim Kochen bleiben die Lösungsgemische ganz klar. Es entsteht nur ein sehr zäher Schaum (wie bei Quecksilberchlorid) und die Absorption im Roth wird schwächer.

\section{Mercurich 1 or id.}

Hämoglobinlösungen verschiedenster Concentration werden durch Sublimat nicht getrübt. Lässt man eine mit ihrem Volum kalt gesättigter stark sauer reagirender wässeriger Quecksilberchloridlösung versetzte Lösung von Hämoglobin bei $10^{\circ} \mathrm{C}$. an der Luft stehen, so wird die Lösung sehr schnell dunkelroth mit einem Stich in's Braune. Sie zeigt ein Absorptionsband von 44--52 neben den Sauerstoffblutbändern. Mehrere Stunden später bei derselben Temperatur sieht man im Spectrum nur den Streifen im Roth und die Flüssigkeit, welche auch nach Tagen an der Luft und beim Erhitzen zum Sieden ganz klar bleibt, ist braunroth gefärbt. Auch solche ganz frisch bereitete mit Sublimat im Ueberschuss versetzte Blutrothlösungen, welche im Spectrum nur die beiden arteriellen Blutbänder zeigen, gerinnen beim Erwärmen nicht. Erst nach einigen Tagen scheiden sich Flocken aus der gekochten Lösung. Beim Lrwärmen beobachtet 
man eine sehr: lebhafte Schaumbildung, nach dem Erwärmen nur den Absorptionstreifen im Roth. Der weisse Schaum ist sehr zähe und haftet dem Glase fest an.

\section{Platinchlorid.}

Concentrirte schwach sauer reagirende wässerige Platinchloridlösung erzeugt in geringen Mengen voluminöse orangegelbe Niederschläge, welche beim Erwärmen zu dunkelbraunen Flocken zusammenschrumpfen, sich beim Kochen mit einem Ueberschuss des Fällungsmittels nicht lösen.

\section{A urichlorid \\ (in Wasser).}

Saures Goldchlorid verhält sich wie Platinchlorid, nur ist der Niederschlag schon gleich anfangs dunkel gefärbt.

\section{Cuprisulphat.}

Giesst man vorsichtig tropfenweise in ein Probirglas zu einer Sauerstoffhämoglobinlösung deren Volum concentrirtes kaltes Kupfervitriol, so sammelt sich letzteres unter der rothen Flüssigkeit ohne die geringste Trübung an und man erhält drei klare allmählich in einander übergehende Schichten : unten das blaue Kupfervitriol, dann eine grüne Schicht, und oben das rothe Hämoglobin. Beim Schütteln wird die ganze Lösung prachtvoll grün gefärbt und zeigt oft noch einige Minuten lang im Spectrum die Sauerstoffhämoglobinstreifen. Das Roth ist aber (bis 53) sehr stark absorbirt. Beim Kochen bleibt die Lösung klar und die grüne Farbe auch nach dem Abkühlen unverändert.

\section{Cuprichlorid}

verhält sich ganz ähnlich dem Kupfersulphat. Iie Sauerstoffhämoglobinstreifen werden noch schneller ausgelöscht.

Kupferacetat

wie Kupferchlorid. Nur bleiben die Sauerstoffstreifen viel länger sichtbar.

\section{Silbernitrat.}

Hämoglobinlösungen sind in der Kälte mit Höllensteinlösungen in jedem Verhältniss ohne die geringste Trübung mischbar und das 
optische Verhalten der Lösung wird anfangs, abgesehen von der Verdünnung, nicht verändert. 'Tritt in Hämoglobinlösungen durch Silbernitrat eine Trübung ein, so sind sie entweder nicht rein oder die Silberlösung enthält freie Säure. Lässt man ein Gemisch von reiner Hämoglobin- und reiner Silbernitratlösung bei 9 bis $10^{\circ} \mathrm{C}$. an der Luft stehen, so zersetzt sich das Hämoglobin nach wenigen Stunden, die Farbe wird bräunlich und die Hämoglobinstreifen werden ausgelöscht. Beim Erwärmen verschwinden sie fast augenblicklich und die Lösung wird röthlich-bräunlich-gelb mit einem grünen 'T'on. Beim Sieden und nachherigem Abkühlen bleibt sie durchaus klar. Während des Erwärmens tritt ein Absorptionstreif im rothen Theil des Spectrum auf. C. Schmidt giebt an, Hämoglobin werde aus concentrirter und verdünnter Lösung von Silbersalzen gefällt. Diese unrichtige Angabe erklärt sich wahrscheinlich durch Unreinheit der Substanz (oder der Reagentien). Auch seine Angabe, Quecksilbersalze fällten das Hämoglobin, ist unrichtig.

\section{Silbersulphat.}

Mischt man eine kalt gesättigte Silbersulphatlösung mit einer wässerigen Hämoglobinlösung, so tritt keine Trübung ein und die Sauerstoffbänder verändern sich anfangs nicht. Sehr bald aber werden sie auch in der Kälte ausgelöscht und die Lösung gerinnt beim Erwärmen, auch dann, wenn die Hämoglobinstreifen beim Beginne des Erwärmens nicht mehr sichtbar waren.

Beim längeren Stehen des Flüssigkeitsgemisches in der Kälte entsteht gleichfalls eine Trübung, die nach und nach zunimmt. Es scheiden sich dann rothe, im Sonnenlicht grau werdende Flocken aus, die sich zusammenballen, zu Boden sinken und am Licht dunkelrothbraun werden. Zugleich wird die Flüssigkeit klarbraun und zeigt einen Absorptionstreif bei 50 .

\section{Ferrichlorid.}

Concentrirte käufliche sauer reagirende Eisenchloridlösung: bewirkt in Sauerstoffhämoglobinlösungen weder Trübung noch Fällung in der Kälte. Aber es wandelt die Farbe der Lösung augenblicklich in Braun um, die Hämoglobinstreifen verschwinden und es tritt ein Band von 43-49 auf. Auch dieses verschwindet beim Erwärmen und beim Kochen trübt sich das Lösungsgemisch. Es wird ganz undurchsichtig und gelb. Das Gerinnsel setzt sich auch nach 
Tagen nicht $a b$ (die Flüssigkeit bleibt trübe); es haftet zum Theil sehr fest an den Gefässwandungen und ist in destillirtem Wasser unlöslich.

Auch Meerschweinchenhämoglobinlösungen werden nach Lehmann von Eisenchlorid nicht gefällt. Die Lösung des sauerstoffhaltigen Cyanwasserstoffhämoglobins aber giebt mit Eisenchlorid eine Fällung. Hat die Lösung $0^{0}$, so tritt diese Fällung sehr allmählich ein.

\section{Bleiessig.}

Bleiessig ist in jedem Verhältniss mit Hämoglobinlösungen mischbar, olme dass eine Trübung oder Veränderung der Farbe und des Spectrum bewirkt wird. Lässt man aber das Gemisch einige Minuten in der Kälte stehen, so wird es gelbbraun und im Spectroskop sieht man neben den sehwächer gewordenen, dann ganz verschwindenden Sauerstoffstreifen ein schlecht begrenztes Band etwa bei 52-58. Bleibt die Lösung der Luft ausgesetzt, so trübt sie sich, weil sich Bleicarbonat bildet. Ueber Quecksilber bleibt sie vollkommen klar. Sie bleibt auch klar, wenn man zum Sieden erhitzt und wieder abkühlt. Kohlensäurehaltige oder Serumalbumin enthaltende Hämnglobinlösungen trüben sich mit Bleiessig.

\section{B leizucker.}

Wässerige Bleizuckerlösungen trühen Hämoglobinlösungen nicht. Bei sehr gelindem Erwärmen werden die Sauerstoffhämoglobinstreifen ausgelöscht und die Lösung wird braun. Sie bleibt beim Kochen klar und wird grünlichbraun.

Kaliumbisulphat.

Concentrirte wässerige Iössungen färben in der Kälte die Hämoglobinlösungen schnell braun, die Sauerstoffstreifen verschwinden, es tritt keine Trübung ein, weder in der Kälte noch beim Sieden.

\section{Kaliumsulphocyanid.}

Kleine Mengen kalter höchst concentrirter Rhodankaliumlösungen sind ohne Trübung mit Hämoglobinlösungen mischbar. Das Spectrum bleibt dasselbe. Grössere Mengen löschen die Sauerstoffstreifen aus beim gelinden Erwärmen, die Lösung erhält einen gelbrothen Schimmer, aber ich habe keine charakteristischen Streifen im Spectrum wahrnehmen können, nur in der Gegend der Sauerstoff- 
streifen eine verwaschene Absorption. Beim Sieden trüben sich die Lösungen und beim Abkühlen setzt sich ein rostrother Niederschlag zu Boden. Die darüber stehende Flüssigkeit ist klar.

Kaliumpermanganat.

Einige Tropfen Chamäleonlösung zu einer Sauerstoffhämoglobinlösung gebracht, welche die beiden Absorptionsbänder deutlich getrennt erscheinen lässt, Iöscht diese aus. Es tritt statt dessen ein Absorptionstreifen im Roth auf $(47-51)$. Die Sauerstoffhämoglobinstreifen lassen sich nicht wieder hervorrufen. Die Lösung trübt sich nicht beim Sieden.

Giesst man umgekehrt in eine Chamäleonlösung, welche $5 \mathrm{Ab}$ sorptionstreifen deutlich getrennt erscheinen lässt, tropfenweise Hämoglobinlösung, so schwinden nach und nach jene 5 Bänder und die Sauerstoffhämoglobinstreifen erscheinen. Diese Lösung trübt sich beim Kochen nur, wenn ein Ueberschuss von Hämoglobin angewandt wurde.

\section{$\mathrm{H}$ a r n.}

Sauerstoffhämoglobinlösungen sind mit stark saurem normalem lebenswarmem menschlichem Harn ohne die geringste Trübung oder Veränderung der beiden Absorptionsbänder, abgesehen von der Verdünnung, mischbar. Lässt man jedoch das Gemisch, auch unter $10^{\circ}$ mehrere Stunden stehen, so wird die Lösung braun und es tritt ein Absorptionsband von 48-53 (Methämoglobin) auf. Indessen bleiben auch die Sauerstoffhämoglobinstreifen noch sehr lange sichtbar und die Lösung coagulirt beim Erwärmen. Es erscheint daher um so auffallender die Angabe Valentins (Gebrauch des Spectroskops 1863, 84), dass Hundeharn, der durch Injection von gallensauren Alkalien in das Blut blutig gemacht ist, keine Hämoglobinstreifen liefern soll. Auch der hämaturische Harn eines an acutem Gelenkrheumatismus leidenden Kranken zeigte Valentin das Hämoglobinspectrum nicht. Die von mir spectroskopisch untersuchten hämaturischen Harnproben zeigen dagegen nur dann keine charakteristische Absorption im Spectrum, wenn sie 24 Stunden und mehr alt waren. Frischer hämaturischer Harn aus der hiesigen Klinik zeigte mir, auch wenn er nicht im Mindesten roth gefärbt erschien, doch die Sauerstoffhämoglobinstreifen. Sie verschwinden aber bei gewöhnlicher Temperatur innerhalb 24 Stunden. Ein einfacher Versuch lehrt den 
grossen Unterschied zwischen Blut und Hämoglobin in dieser Hinsicht kennen. Reine Blutkrystalle in Harn aufgelöst bleiben tagelang deutlich spectroskopisch nachweisbar, Blut mit Harn vermischt nur ganz kurze Zeit.

Einwirkung reducirender Substanzen auf Sauerstoff$\mathrm{h} \ddot{\mathrm{am}} \mathrm{og} \mathrm{lobin}$.

Es giebt eine Reihe von leicht oxydabeln Körpern, welche, wie Stokes entdeckte, dem Sauerstoffhämoglobin den locker gebundenen Sauerstoff entziehen. Einige greifen das Hämoglobin dabei nicht weiter an, so dass es durch Zufuhr neuen Sauerstoffs wieder in Sauerstoffhämoglobin übergeführt werden kann, dahin gehört z. B. Zinnoxydul und Ammoniumsulphid in sehr grosser Verdünnung. Andere verändern das Hämoglobin unmittelbar, nachdem sie es reducirt haben, dahin gehören z. B. Kaliumsulphid, Ammoniumsulphid in grösseren Mengen.

\section{Wasserstoffgas und Stickgas.}

Diese beiden Gase sind die einzigen, welche man dem Hämoglobin gegenüber als indifferent bezeichnen darf, insofern sie in der Kälte keine Zersetzung hervorrufen und sich, wie es scheint, nicht mit dem Hämoglobin verbinden. Sie haben abor beide die Eigenschaft, bei sehr anhaltendem Durchleiten auch in der Kälte das Sauerstoffhämoglobin zu reduciren, so zwar, dass beim Schütteln der Lösung mit atmosphärischer Luft wieder Sauerstoffhämoglobin daraus wird. Es ist aber nicht ermittelt, ob beim Behandeln der Sauerstoffhämoglobinlösungen mit Wasserstoff oder Stickstoff der Sanerstoff vollständig a usgetrieben wird oder ob nicht selbst bei ziemlich niedriger Temperatur eine Sauerstoffzehrung stattfindet, so dass, wie I. Hermann meint, nur die Aufnahme neuen Sauerstoffs verhindert, nicht aber sämmtlicher Hämoglobinsauerstoff ausgetrieben wird. Mir scheint, diese Frage beantwortet sich in einfachster Weise: wenn nach anhaltendem Durchleiten von Wasserstoff oder Stickstoff kein Zersetzungsproduct neben dem reducirten Hämoglobin in der Lösung sich befindet, dann ist wirklich sämmtlicher Hämoglobinsanerstoff ausgetrieben, ist aber ausser unzersetztem Hämoglobin zersetztes nach dem Durchleiten vorhanden, dann wurde jener Sauerstoff zum Theil verbraucht, un Oxydationsproducte abzuspalten. 
Ammoniumsulphid.

Wenn man zu einer verdünnten Sauerstoffhämoglobinlösung sehr wenig Schwefelammonium bringt, so verschwinden in der Kälte nach einigen Minuten, bei ganz gelindem Erwärmen fast augenblicklich die Sauerstoffstreifen im Spectrum und es tritt, wie Stokes zuerst sah, das breite, schlecht begrenzte, nach ihm benannte Absorptionsband des sauerstofffreien Hämoglobins auf; durch Zufuhr atmosphärischen Sauerstoffs zu der Lösung kann man aber bekanntlich die Sauerstofflämoglobinstreifen wieder hervorrufen.

Fügt man grössere Mengen Schwefelammon zu Sauerstoffhämoglobin, so wirkt es augenblicklich reducirend, aber, wie schon Stokes wusste und Nawrocki (Med. Centralbl. 1867, S. 176) später des Genaueren hervorhob, nicht ohne Zersetzung; denn sowie das Reductionsband sichtbar wird, tritt im Roth ein Streifen auf, der mit dem Schwefelwasserstoffband nicht identisch ist. Er liegt bei 51-55 und ist nicht scharf begrenzt. Nun kann man durch Sauerstoffzufuhr die Sauerstoffstreifen nicht mehr hervorrufen. Sehr bald tritt auch in der Kälte eine weitere Veränderung des Spectrum ein: der Reductionstreifen wird tiefschwarz, sehr schmal und ausserordentlich scharf begrenzt, neben ihm erscheint ein weniger schwarzer schlecht begrenzter Streifen. Die Lage dieser Streifen (Taf. IX Fig. 13 ) ist $66,5-73,5$ (in verdünnten Lösungen $67-71$ ) und $77-83$ (verdünnt 77-81). Die Streifen verändern sich gewöhnlich nicht beim Schütteln mit Luft und bei gelindem Erwärmen, bei weiterem Erwärmen coagulirt die Lösung. Ich habe aber dennoch dies e beiden Streifen des reducirten Hämatins in die des Sauers toffhämoglobins zurückverwandeln können, indem ich zu 1 Vol. einer Sauerstoffhämoglobinlösung, die in sehr dicker Schicht die beiden Streifen sehr deutlich getrennt erscheinen lässt, 1 Vol. Ammoniakflüssigkeit (spec. Gew. 0,925) und 1 Vol. kalt gesättigten Schwefelwasserstoffwassers brachte. Das Gemisch blieb eine Viertelstunde bei $9^{0} \mathrm{C}$. in einem verschlossenen Gefässe im Tageslichte stehen. Es zeigte dann bräunlich geworden die drei von Nawrocki beschriebenen Streifen. Beim Schütteln mit Luft verschwanden alle 3 und es traten die Sauerstoffhämoglobinstreifen auf; nach wenigen Minuten erscheint wieder der scharf begrenzte schmale Streif, unmittelbar danach der neben ihm gelegene. Der dritte im Roth (51-54) tritt, wenn man ordentlich mit Luft geschüttelt hat, 
nicht wieder auf und die beiden anderen verschwinden nach etwa zwei Tagen auch in der Kälte (8 bis $10^{\circ} \mathrm{C}$.). Man kann dann durch Zufuhr atmosphärischen Sauerstoffs die Sauerstoffhämoglobinstreifen nicht wieder hervorrufen. Diese Lösung gerinnt nicht beim Kochen. Die Streifen bleiben danach länger sichtbar.

Kaliumsulphid.

Sehr ähnlich dem Schwefelammon wirkt das Schwefelkalium auf Sauerstoffhämoglobin. Ich habe die Veränderung des Spectrum bereits früher beschrieben (Med. Centralbl. 1867 S. 274 u. "Blausäure " S. 86, 105) und verweise nur auf die Abbildung desselben Taf. IX Fig. 13. Die beiden Absorptionstreifen sind identisch mit den von Stokes entdeckten des reducirten Hämatins. Man erhält sie auch durch Behandeln von Blut mit heisser Kalilauge.

Natriumsulphid.

Von allen zur Reduction des Sauerstoffhämoglobins sich eignenden Mitteln ist keines so vortheilhaft zu brauchen als Schwefelnatrium. Es ist farblos, leicht rein und krystallisirt zu erhalten, eine Verbindung von bekannter constanter Zusammensetzung und wirkt mit der grössten Energie.

\section{Z in nox y d u l.}

Wenn man ein Milligramm des stark sauer reagirenden käuflichen Zinnsalzes $\left(\mathrm{SnCl}_{2}+\mathrm{xH}_{2} \mathrm{O}\right)$ in einige Cubiccentimeter verdünnter wässeriger Sauerstoffhämoglobinlösung bringt, so treten dieselben Veränderungen wie nach Zusatz minimaler Salzsäuremengen ein: die Hämoglobinstreifen verschwinden, ohne dass das Reductionsband auftritt, die Lösung wird braun, sie zeigt das Salzsäureband 44-48 (concentrirter 43-4.9, ganz concentrirt 41-51). Die Lösung bleibt beim Kochen klar, durch Schütteln mit Luft lassen sich die Sauerstoffbänder nicht wieder hervorrufen. Man kann daher zur Reduction nicht das Zinnsalz als solches anwenden. Auch die saure wässerige Lösung ist unbrauchbar, eben weil sie sauer reagirt und das Zinnsalz sich zersetzt, sich weisses unlösliches Zinnoxychlorid ausscheidet. Stokes wandte daher eine weinsaure Lösung an, die schwach alkalisch gemacht wurde. Man pflegt sich neutrale Lösungen zu bereiten durch Zusatz von Weinsäure zum Zinnsalz und Neutralisiren mit Ammoniak. Man erhält so eine klare Lösung von 
Unterzinntartrat (Stannotartrat), Ammoniumtartrat und Salmiak in Wasser. Das Stannotartrat wirkt reducirend ohne weiter in der Kälte zu zersetzen. Durch Sauerstoffzufuhr erhält man wieder die Sauerstoffhämoglobinstreifen. Wie Stokes mit Recht hervorhebt, hat also das reducirte Hämoglobin eine stärkere "Verwandtschaft، zum freien Sauerstoff der Luft als Zinnoxydul und doch entzieht dieses dem Sauerstoffhämoglobin den Sauerstoff. Dieses eigenthümliche Verhalten gilt für alle das Sauerstoffhämoglobin reducirende Substanzen, welche nicht durch Austreibung, sondern Bindung des Hämoglobinsauerstoffs reduciren.

Mit der neutralen Zinnlösung versetzte Hämoglobinlösungen halten sich, wie Nawrocki angiebt, wochenlang unzersetzt an der Luft.

\section{Ferrosulphat.}

Stokes fügte zu einer Eisenvitriollösung soviel Weinsäure, dass das Gemisch von Alkalien nicht gefällt wurde. Ein kleiner Theil der Flüssigkeit mit Ammon, besser jedenfalls mit Soda alkalisch gemacht, zu Blut- oder Sauerstoffhämoglobinlösung gebracht, wandelt deren Farbe sehr schnell in ein dunkleres Roth um, und es erscheint das Spectrum des sauerstofffreien Hämoglobin. Durch Schütteln mit atmosphärischer Luft erhält man wieder das Spectrum des Sauerstoffhämoglobin.

\section{Reducirende St of fe im Blute.}

Wenn man wässeriges Cruorextract in einer verkorkten Flasche oder auch in einem hohen schmalen oben offenen Gefässe bei gewöhnlicher Temperatur einige Zeit stehen lässt, so wird die Farbe dunkeler und in dünnen Schichten purpurn, ohne dass irgend ein Fäulnissgeruch wahrnehmbar wäre. Das Spectrum des unteren Theiles der Lösung ist das des reducirten Hämoglobin, welches sich durch Sauerstoffzufuhr wieder in Sauerstoffhämoglobin umwandelt. Stokes schloss aus dieser Beobachtung, es müssten wohl im Blute Stoffe vorhanden sein, die sich auf Kosten des Sauerstoffhämoglobins oxydirten. Diese Vermuthung ist aber nicht begründet, denn ich habe a bsol u t r ei ne wässerige Sauerstoffhämoglobinlösungen bei niedriger Temperatur in einem luftdicht verschlossenen Gefässe, welches keine Luft und eben nur das reinste Sauerstoffhämoglobin in destillirtem Wasser enthielt, bei einigen Grad über 0 stehen lassen und gefun- 
den, dass am dritten Tage die Farbe dunkeler wurde, am 10. Tage war in der ganzen Lösung, die purpurn gefärbt erschien, kein Sauerstoffhämoglobin vorhanden, statt dessen erschien das breite, auch in dünnen Schichten der Lösung sehr dunkele Band des reducirten Hämoglobins ( 37 bis 58 hell, 58 bis 77 dunkel, 77 bis 123 hell) und durch Schütteln mit Luft ward die Farbe und das Spectrum wieder arteriell. Hieraus geht nun nicht hervor, dass das Blut keine reducirenden Substanzen enthält, es ist aber durch diese Beobachtung bewiesen, dass auch in der Kälte das Sauerstoffhämoglobin seinen locker gebundenen Sauerstoff selbst verbraucht. In der That kann man sich durch das Spectroskop von dem Vorhandensein eines Zersetzungsproductes in der übrigens globinhaltigen Lösung leicht überzeugen, aber nur bei Anwendung sehr concentrirter Lösungen oder sehr dicker Schichten verdünnter Lösungen. Man sieht dann nämlich einen Absorptionstreifen von 46 bis 49 , also gerade an der Stelle, welche durchaus unzersetztes Hämoglobin in concentrirtester Lösung von allen Lichtarten allein nicht auslöscht.

Die Sauerstoffzehrung in reinen wässerigen Hämoglobinlösungen ist also von einer Zersetzung des Farbstoffs begleitet: es bildet sich eine neue Verbindung. Man kann daher auch wenn eine wässerige Blutlösung für sich oder nach Zusatz von etwas Ammon auf 40 bis $50^{\circ}$ erwärmt worden ist und dann statt der Sauerstoffstreifen das Stokessche Absorptionsband zeigt, (welches in jene beim Luftzutritt sich wieder umwandelt) nicht schliessen es seien reducirende Substanzen im Blute. Auch hier kann die Sauerstoffzehrung möglicherweise lediglich auf Rechnung des Hämoglobins kommen oder es können sich durch das Erwärmen in dem mit Ammoniak versetzten Blute reducirende Stoffe erst neu gebildet haben.

Wenn eine wässerige Sauerstoffhämoglobinlösung ohne Luft in luftdichtem Verschluss gehalten wird, so hört nachdem das Hämoglobin seinen Sauerstoff verbraucht hat, die Zersetzung auf. Die Lösung hält sich allen Temperaturen des Bonner Klimas ausgesetzt über ein Jahr vollkommen unverändert.

Metalle.

Rollett hat gefunden, dass frisches durch Schlagen an der Luft entfasertes und sauerstoffreich gemachtes Blut dunkelroth und sauerstofffrei wird, wenn man es kurze Zeit mit einigen Metallen in sehr feiner Vertheilung unter Luftabschluss schüttelt. Die Me- 
talle sind Fisen, Zinn, Blei, Antimon. Viel langsamer reducirt Silber, gar nicht Platin und Quecksilber. Nach der Einwirkung der Eisenfeile zeigt das Blut den Stokesschen Streifen und wird durch Luft wieder hellroth, indem es wieder die Sauerstoffhämoglobinstreifen zeigt. Die Einwirkung der feinvertheilten Metalle beruht nicht lediglich auf Zerstörung der Blutkörperchen, sondern auf wirklicher Sauerstoffentziehung. Denn wenn arterielles Blut mit kurz abgebrochenen Asbestfäden unter Luftabschluss geschüttelt wird, so verliert es seinen Sauerstoff nicht. Es wird lackfarben, behält aber sein Spectrum (Sitzungsber. d. Wien. Ak. LIl, 1865).

Ueber das Verhalten des Sauerstoffhämoglobins zu einigen Alkoholen, zum Aether, Chloroform, Terpenthinöl und Schwefelkohlenstoff.

\section{Aethylalkohol.}

Kleine Mengen absoluten Alkohols sind in der Kälte ohne Trübung und Aenderung des optischen Verhaltens auch mit concentrirten Blutfarbstofflösungen mischbar. Fügt man aber vorsichtig nach und nach mehr Alkohol zu der rothen Flüssigkeit, so tritt ein Punct ein, wo man an der Grenze zwischen dieser und dem farblosen Alkohol eine eiweissartige Ausscheidung sieht. Beim Umschütteln erhält man wieder eine klare rothe homogene Lösung. Wird mit dem Alkoholzusatz so lange fortgefahren bis die Trübung beim Umschütteln nicht mehr verschwindet, so kann man sie durch reichlichen Zusatz destillirten Wassers anfangs noch schwinden machen und erhält dann wieder eine klare Lösung, welche die beiden Sauerstoffhämoglobinstreifen zeigt. Bleibt die durch Alkohol getrübte Hämoglobinlösung bei etwa $9^{\circ} \mathrm{C}$. stehen, so setzt sich der schmutzig rothe Niederschlag zu Boden, die darüberstehende Flüssigkeit bleibt aber trübe.

Es scheint das Sauerstoffhämoglobin des Hundes in Wasser durch Alkohol amorph gefällt werden zu können, ohne dass sofort Zersetzung eintritt. S. auch S 407. Trägt man frische Blutkrystalle in ammoniakhaltigen concentrirten Alkohol, so gelingt es zwar bei gelindem Erwärmen eine klare eiweissfreie Hämatinlösung darzustellen, die coagulirten Albuminstoffe aber habe ich trotz tagelangen Auswaschens nicht vollkommen hämatinfrei erhalten. Sie hinterlassen stets noch nachweisbare Spuren von Eisen beim Veraschen und sind auch nicht vollkommen weiss. 


\section{Amylalkohol.}

Schüttelt man in einem Probirglase eine wässerige Lösung reinen Sauerstoffhämoglobins mit überschüssigem Amylalkohol, so erhält man eine gleichmässige gelblich fleischfarbene Masse, welche sich nach einiger Zeit in der Kälte in drei Schichten sondert, eine obere, farblose, durchsichtige, flüssige: Amylalkohol, dann eine feste, gallertige schmutzig braune Schicht. Giesst man den Amylalkohol $a b$, so kann das Probirglas umgekehrt werden, ohne dass etwas ausfliesst. Durch starkes Schütteln lockert sich das feste dunkelbraune Coagulum von der Gefässwandung und man kann die letzte Schicht, welche hellroth gefärbt ist, ausgiessen. Sie besteht aus Wasser, fein vertheiltem Amylalkohol und amorphem allem Anschein nach unzersetztem Hämoglobin. Aus dem elastischen sehr dunkelrothbraunen Gerinnsel lässt sich eine erhebliche Menge farblosen Amylalkohols auspressen. Es wird dabei schwarz und nimmt ungemein an Volumen ab.

Hieraus geht mit Wahrscheinlichkeit hervor, dass durch feine Vertheilung von Amylalkohol in wässerigen Lösungen des Hämoglobins, dieses anfangs grossentheils unzersetzt in amorphem $\mathrm{Zu}$ stande gefällt wird.

\section{Glycerin.}

Versetzt man eine wässerige Lösung von reinen Blutkrystallen mit durchaus reinem Glycerin, so sammelt sich dieses unter der rothen Lösung an und bleibt farblos. Beim Umschütteln aber mischen sich die beiden Flüssigkeiten leicht und das Gemisch bleibt an der Luft unter $10^{\circ}$ sehr lange unzersetzt. Erst nach sechs Tagen Stehens an der Luft (bei 8 bis $1^{\circ}$ ) war eine ganz schwache Andeutung einer Absorption im Roth bemerkbar.

Wasserhaltiges Glycerin ist ein treftliches Lösungsmittel für die Blutkrystalle des Hundes. Beim Erwärmen verschwinden schnell die Sauerstoffstreifen im Spectrum und die Lösung coagulirt unter Entfärbung.

\section{Aethyläther.}

Schüttelt man eine wässerige Hämoglobinlösung im Probirglas mit Aether, so erhält man eine undurchsichtige trübrothe Masse, 
die aber nach wenigen Secunden sich in eine obere farblose Aetherschicht und eine untere rothe gallertige Schicht trennt. Bald zieht sich die Gallerte zusammen und bleibt an der Grenze suspendirt als eine zusammenhängende Masse. Nach mehreren Stunden (bei 9 bis $11^{\circ}$ C.) kann man häufig die Probirröhre umkehren, ohne dass etwas ausfliesst und bemerken, dass die ganze Aetherschicht in eine schmutzigrothe Gallerte verwandelt ist, während die vorher wässerige Schicht unten, weniger stark gefärbt, neben den Sauerstoffhämoglobinbändern einen Absorptionstreifen im Roth (49-53) zeigt. Beim Schütteln wird die Gallerte gelockert und grosse ungleichmässig gefärbte Klumpen schwimmen in einer misfärbig rothen Flüssigkeit, die sich nun nicht mehr in zwei Schichten sondert.

Aether zersetzt Hämoglobin in eine Gallerte, die ganz farblos ist und in einen rothbraunen Farbstoff, der jener mechanisch anhaftet, so dass sie ungleichmässig gefärbt erscheint. Diese Zersetzung ist indessen möglicherweise nicht dem Aether, sondern dem Antozon zuzuschreiben. Die gallertigen Klumpen sind sehr leicht löslich in Eisessig.

\section{Chloroform.}

Wird eine wässerige Blutkrystallösung im Probirrohr mit reinem, neutralem Chloroform geschüttelt, so sondert sich letzteres hell fleischfarben von jener ab. Nach einigen Stunden (bei etwa $10^{\circ}$ ) ist die rothe Flüssigkeit blassroth und in ihr ein fleischfarbener Niederschlag sichtbar. Giesst man den Niederschlag ab, so kann man das Röhrchen umkehren ohne dass Chloroform ausfliesst. Der Rückstand ist gallertig. Das Spectrum der rothen Lösung ist unverändert das des Sauerstoffhämoglobins. Durch Schütteln trennt sich die Gallerte in eine farblose Chloroformschicht und ein fleischfarbenes Gerinnsel. Aus diesen Reactionen ergiebt sich, dass durch Schütteln mit Chloroform das Hämoglobin als fleischfarbenes flockiges Gerinnsel aus seinen wässerigen Lösungen ausgeschieden wird. Durch anhaltendes Schütteln mit genügenden Mengen Chloroform kann man wässerige Hämoglobinlösungen vollkommen entfärben. Zwischen dem farblosen Chloroform und der farblosen Flüssigkeit befindet sich dann sämmtliches Hämoglobin als fleischfarbene, amorphe Flöckchen, welche ihre schöne Farbe bei etwa $8^{0}$ C. viele (bis 8) Tage lang behalten. Sie lösen sich nicht in Wasser. 
Terpenthinöl.

Schüttelt man sehr stark eine concentrirte Hämoglobinlösung mit wenig Terpenthinöl, so scheidet sich letzteres zwar in der Ruhe farblos über ersterer $a b$, aber in der rothen Lösung hat sich eine gallertige Masse ausgeschieden und sie wird nach kurzer Zeit, wahrscheinlich durch Ozonwirkung, sehr dunkel, fast schwarz gefärbt.

\section{Schwefelkohlenstoff.}

Durch Schütteln einer Hämoglobinlösung mit Schwefelkohlenstoff wird keine Ausscheidung und keine Veränderung des Spectrum bewirkt. Erst nach 5 bis 6 Tagen bemerkte ich neben den Sauerstoffbändern eine Absorption zwischen $\mathrm{C}$ und $\mathrm{D}$ bei $50-55$. Temp. etwa $11^{\circ} \mathrm{C}$. Der Schwefelkohlenstoff bleibt völlig farblos unter der rothen Lösung liegen.

Einwirkung der Halogene auf Sauerstoffhämoglobin.

Chlor, Brom und Jod fällen nach C. Schmidt das Hämoglobin aus concentrirter und verdünnter Lösung.

Nach Lehmann entfärbt Chlorgas die wässerige Lösung der Meersehweinchenblutkrystalle fast augenblicklich und präcipitirt weisse Flocken. Jodwasser ändert nach ihm nur die Farbe der Flüssigkeit. Ich finde folgendes:

Chlorwasser bewirkt durchaus keine Trübung, aber augenblicklich Farbenänderung. Die vorher arteriellroth gefärbte Lösung wird sofort grünbraun. Im Spectrum sind keine charakteristischen Absorptionstreifen wahrnehmbar. Lässt man die Lösung bei 8 bis $10^{0}$ dem Lichte ausgesetzt stehen, so entfärbt $\cdot$ sie sich vollständig und es scheidet sich ein blassgrünlich weisses Gerinnsel aus. Die mit Chlorwasser versetzte und dann einen Augenblick gekochte Hämoglobinlösung bleibt klar, es scheidet sich nichts aus, sie entfärbt sich nicht vollständig auch nach Tagen nicht.

Reines Brom wirkt schon in minimalen Merigen zerstörend auf Hämoglobin ein. Fin Tropfen zu mehreren Cubiccentimetern einer concentrirten Lösung gebracht färbt sie augenblicklich sehr dunkel und es entsteht ein Gerinnsel, welches ungleichmässig gefärbt in einer schmutzig braunen Flüssigkeit (nach Verdünnen mit destillirtem Wasser) schwimmt. Letztere zeigt keine charakteristischen Absorptionen im Spectrum. Lässt man das Gemisch dem Lichte ausgesetzt bei 8 bis $10^{\circ}$ stehen, so trennt es sich nach einigen Stun- 
den in vier Schichten: oben befindet sich eine klare gelbe Schicht (Bromwasser), dann folgt das gelbe Coagulum, hierauf eine gesättigt rothgelbe Schicht und unten der Bromtropfen. Das Gerinnsel zieht sich allmählich stark zusammen und steigt an die Oberfläche.

Reichliche Mengen frischbereiteten Bromwassers bewirken in wässerigen Hämoglobinlösungen, wenn sie ganz rein sind, keine Trübung, aber es wird (durch die Farbe des Bromwassers) die Farbe braunroth. Die Sauerstoffhämoglobinstreifen schwinden fast augenblicklich und es tritt eine verwaschene Absorption an ihre Stelle. Beim Kochen hellt sich die Lösung bedeutend auf und nimmt ganz die Farbe des Bromwassers selbst an. Die verwaschene Absorption schwindet. Ich habe keinen anderen Absorptionstreifen bemerkt. Das Flüssigkeitsgemisch bleibt beim Kochen und nachherigem Abkühlen ganz klar.

Ganz wie Bromwasser verhält sich Jod wasser.

Eiweissreactionen.

Obgleich das Hämoglobin kein AJbuminstoff ist, so gibt es doch mehrere Reactionen, welche man als die für Eiweissstoffe charakteristischsten anzusehen gewohnt ist. So wird z. B. das krystallisirte Hämoglobin vom Hunde, dessen wässerige Lösung nicht von Quecksilberchlorid, nicht von Silbernitrat, nicht von Eisenchlorid, nicht von Bleiessig getrübt wird, stets die $\mathrm{X}$ anthoproteinreaction geben. Die Millonsche Reaction ist mit Lösungen anstellbar, die so verdünnt sind, dass man nur gerade noch eine Färbung sieht. Stets wird die eigenthümlich rothe Farbe an dem Gerinnsel beim Erwärmen zum Vorschein kommen.

Versetzt man ein wenig Hämoglobinlösung mit Kalilauge und einem Tropfen Kupfervitriol, so wird, wie bei Eiweissstoffen, die Lösung beim Erwärmen violett.

Während ferner Essigsäure für sich und Ferrocyankalium für sich einer reinen Hämoglobinlösung zugesetzt keine Trübung bewirken, erhält man einen weissen albuminösen Niederschlag, wenn man beide zusammen in die Lösung bringt; dasselbe gilt vom Bleizucker und Ammoniak.

Trotzdem nun das Hämoglobin die eigenthümlichen Eiweissreactionen zeigt, können wir es nicht zu den Albuminstoffen zählen, dem widerspricht unter anderem allein schon der Eisengehalt. Wir müssen vielmehr folgern, dass bei jeder der genannten Albuminpro- 
ben das Blutroth in der Weise zersetzt wird, dass Eiweiss sich abspaltet. Gerade hierin besteht eine der räthselhaftesten Sonderbarkeiten des Hämoglobins, denn wir kennen ausser ihm keinen krystallisirbaren Körper, welcher unter seinen Zersetzungsproducten Albumine aufweisen könnte. Es genügen die geringfügigsten Eingriffe um aus frischen Blutkrystallen Eiweiss abzuspalten, z. B. blosses Erwärmen, so dass wir (siehe oben S. 411) nicht behaupten dürfen, das Hämoglobin selbst gerinne beim Erwärmen seiner wässerigen Lösung. Ein in mancher Hinsicht dem Eiweiss nahestehendes, in anderer sehr davon abweichendes Zersetzungsproduct des reinen Hämoglobins ist das von Hoppe-Seyler entdeckte Methämoglobin. Ich habe einige Reactionen mit diesem Körper angestellt, die hier Platz finden mögen.

\section{Das Methämoglobin.}

Wenn man vollkommen reine sehr feingepulverte Hämoglobinkrystalle lange Zeit, etwa einige Monate, über concentrirter Schwefelsäure in einem bedeckten Gefässe stehen lässt, so verändern sie ihre Farbe, und ihre chemischen Eigenschaften. Die Farbe geht von dem anfünglichen intensiven Blutroth in ein misfarbiges Braunroth über und das Pulver ist in kaltem und warmem destillirtem Wasser nur theilweise löslich. Filtrirt man die braun gefärbte Lösung, in welcher die kleinen ungefärbten unlöslichen Partikel schwimmen, so erhält man auf dem Filter einen Eiweissstoff, den ich G10bin nannte (siehe oben S. 410), und in dem klaren braun gefärbten Filtrat einen eiweissartigen aber eisenhaltigen Stoff, das Methämoglobin (Hoppe). Das vollkommen klare Filtrat zeigt folgende Eigenschaften. Es reagirt sehr schwach sauer. Es zeigt das Spectrum Taf. IX Fig. 16. Der Methämoglobinstreif liegt bei 47-521/2. Ausser ihm sieht man meist die beiden Sauerstoffhämoglobinstreifen beim Verdünnen, wobei der Methämoglobinstreifen schwächer wird. Es ist mir indessen auch vorgekommen, dass die Lösungen absolut hämoglobinfrei waren. Erwärmt man die Lösung allmählich, so trübt sie sich stark bei $46^{\circ}$, verdünnte Lösungen erst bei $48^{\circ}$, und die Trübung nimmt mit der Temperatur sehr bedeutend zu bis bei $60^{\circ}$, in verdünntenLösungen bei $68^{\circ}$ bis $70^{\circ}$, Flocken sich bilden und die Flüssigkeit klar wird. Die Flocken sind in concentrirter und verdünnter Essigsäure sehr leicht löslich. Sie sind auch in verdünnter Natronlauge löslich. Die essigsaure Lösung, welche beim Erwärmen 
nicht coagulirt, ist durch eine Lösung von Natriumcarbonat fällbar. Die Fällung löst sich auf, wenn man Natronlauge zufügt und die klare Lösung gerinnt nicht beim Erwärmen. Löst man die Flocken in verdünnter Natronlange, so kann man sie durch Neutralisiren mit Essigsäure wieder abscheiden, ein Ueberschuss von Essigsäure löst sie aber wieder auf. Das Coagulat ist in Kochsalzlösung- unlöslich.

Aus dem klaren Filtrat wird, wie ich finde, ausser durch Temperaturerhöhung das Methämoglobin unter Zersetzung gefällt durch Bleizuckerlösung mit Ammon,

" Alkohol (die Fällung in Essigsäure löslich),

" verdünnte Salpetersäure,

" Salzsäure (Fällung in übersch. Salzsäure in der Wärme klar löslich),

" Essigsäure und Kaliumferrocyanid,

" Silbernitrat, endlich

" Schütteln mit Aether, mit Schwefelkohlenstoff und mit Chloroform;

keine Fällung und keine Trübung entsteht, wenn man der Lösung zusetzt:

Bleizuckerlösung für sich,

Kalkwasser,

Ferrichlorid.

Durch Bleiessig wird Methämoglobin nicht gefällt. Nur manchmal entsteht langsam eine mir bisher unerklärliche schwache Trübung, die im Ueberschuss des Bleiessigs unlöslich und zu unterscheiden ist von Bleicarbonat, das erst nach längerem Stehen an der Luft sich bildet.

Nach Hoppe-Seyler ist dagegen Methämoglobin fällbar durch Bleiessig, wird aber durch einen geringen Ueberschuss des Fällungsmittels gelöst, was ich nicht bestätigen kann.

Sublimat erzeugt nur, wenn reichlich zugesetzt, eine Trübung, die beim Verdünnen mit Wasser schwindet.

Lässt man aber die Lösung von. Methämoglobin in sehr viel wässeriger Sublimatlösung mehrere Tage an der Luft stehen, so scheiden sich braune Flocken aus und die Masse wird gallertig. War das Lösungsgemenge von. Methämoglobin und Mercurichlorid vorher gekocht worden, dann bleibt es an der Luft wochenlang unverändert, klar. Auch das Spectrum unverändert. 
Das Methämoglobin giebt ferner in ausgezeichneter Weise in minimalen Mengen die Millonsche Reaction $r$ Es zeigt auch die Xanthoproteïnreaction. Es giebt auch mit Natronlauge im Ueberschuss und einem Tropfen Kupfervitriol versetzt eine violette Färbung. Dampft man die braune Lösung, die vom Globin durch Filtriren befreit ward, ein und verascht, so bleibt reines Eisenoxyd zurück. Lässt man die Lösung gefrieren, so entsteht keine Trübung beim langsamen Aufthauen, man bemerkt keinerlei Ausscheidungen. Fügt man zu einer sehr concentrirten Auflösung von Methämoglobin in Wasser etwa ein Viertel des Volumens absoluten Alkohol und bringt das Gemisch in eine Kältemischung, so scheidet sich ein grosser Theil des Methämoglobins in sehr fein vertheilten mikroskopischen Flocken aus, die zu filtriren mir nicht gelang. Sie setzen sich zu Boden und die darüberstehende Flüssigkeit stellt eine weniger concentrirte weingeistige Methämoglobinlösung dar, aus der Krystalle zu erhalten mir bisher nicht glückte. Auch Sauerstoffhämoglobinlösungen, welche Methämoglobin enthalten, krystallisiren nicht oder nur sehr unvollkommen, daher, wie Hoppe-Seyler bemerkt, die früheren vergeblichen Bemühungen das Hämoglobin mehrmals umzukrystallisiren. Es bildete sich stets mehr amorphes Methämoglobin, welches die Krystallisation hindert.

Die braune Farbe und das Spectrum einer Methämoglobinlösung verändert sich bei anhaltendem Schütteln mit Luft nicht. Dagegen ist es auffallend, wie ungemein leicht durch Zusatz minimaler Mengen verschiedener Stoffe der Methämoglobinstreif ausgelöscht wird, so z. B. sofort durch Ammoniakwasser (die Mischung bleibt beim Kochen klar und giebt mit Essigsäure eine eiweissartige Fällung), durch Schwefelwasserstoffwasser.

Wird Ammoniumsulphid zu einer Methämoglobinlösung gebracht, so verschwindet auch bei Anwendung ganz concentrirter Lösungen das Methämoglobinband augenblicklich und kommt durch Schütteln mit Luft nicht wieder zum Vorschein. Es tritt dagegen ein schmaler Streifen im Roth auf $(50-53)$.

Auch Borax in reichlicher Menge zu wässeriger Methämoglobinlösung gebracht löscht sofort den Absorptionstreifen aus ohne Trübung. Das Gemisch bleibt beim Kochen klar. Beim Abkühlen aber trübt es sich. Wird eine wässerige Borsäurelösung zu einer Methämoglobinlösung gebracht, so verschwindet der Absorptionstreif auch bei gelindem Erwärmen nicht. Bei weiterem Erwärmen coa- 
Ueber einige Figenschaften des Hämoglobins und des Methämoglobins. 45I

gulirt die Lösung. Sie wird farblos und es scheiden sich braune Flocken aus.

Den Absorptionstreifen, welchen wässerige Methämoglobinlösungen im Roth zeigen, hat man für gleich gehalten dem des Hümatin in saurer Lösung. Und darauf sich stiitzend die Möglichkeit erörtert, dass das Methämoglobin ein Gemenge von Hämatin und Eiweiss sei, welches vielleicht durch das in Methämoglobinlösungen vorhandene Sauerstoffhämoglobin in Lösung gehalten werde. Da diese Vermuthung vor allem auf der Annahme beruht, dass Methämoglobinlösungen nicht hämoglobinfrei sind und auf der Gleichheit der Spectra sich aufbaut, so ist sie zu verwerfen, denn weun man dem Hämoglobin nur Zeit lässt sich zu zersetzen, so erhält man auch ganz hämoglobinfreies Methämoglobin nnd die angenommene Gleichheit der Spectra ist ein Irrthum. Man kann sich auf sehr einfache Weise von der Verschiedenheit der Lage des Methämoglobinstreifens und des Hämatinstreifens überzeugen, wenn man zu einer concentrirten Methämoglobinlösung vor dem Spalt des Spectralapparates ein wenig Säure, z. B. Essigsäure oder Phosphorsäure bringt. Augenblicklich tritt dann eine Verschiebung des Absorptionstreifen nach $\mathrm{B}$ zu ein. Der Methämoglobinstreif liegt bei 47-52 (concentrirter 46-53) das Essigsäureband (Hämatin in saurer Lösung) um 3 bis 4 Theilstriche mehr nach B zu.

Die angesäuerten Lösungen bleiben beim Kochen klar und verhalten sich überhaupt so wie angesäuerte Sauerstoffhämoglobinlösungen. Desgleichen verhalten sich mit Alkalien behandelte Methämoglobinlösungen spectroskopisch ganz so wie Sauerstoffhämoglobin in nicht verdünnten Laugen.

Das trockene Methämoglobin ist in verdünnter Kalilauge besonders bei gelindem Erwärmen leicht löslich. Die kalische Lösung zeigt das Spectrum des Hämatin in alkalischer Lösung. 


\section{Die Spectrumtafel.}

Alle 15 Spectra wurden von mir nach der Natur gezeichnet. Der benutzte Spectralapparat ist ein Bunsen-Kirchhoffscher mit einem Flintglasprisma, photographirter Scala, und Mikrometerschraube am metallenen Spalte. Als Lichtquelle diente entweder directes Sonnenlicht oder eine sehr helle möglichst constante Petroleumflamme. Die Fraunhoferschen Linien bestimmte ich theils direct mittelst des. Sonnenspectrum, tbeils mit Hilfe der durch Chlormetalle gefärbten Gasflamme. Die Natriumlinie diente zum Einstellen (Thistr. 591).

Fig. 1. Fraunhofersche Linien. Sonnenspectrum.

"2-10. Spectra des Sauerstoffhämoglobin ans Hundeblut. Zu allen Spectra, ausgenommen $\mathrm{Nr}$. 10, dienten wässerige Lösungen der Krystalle in einem Hämatinometer von genan $1 \mathrm{~cm}$. Abstand der planparallelen Glaswandungen.

* 2. Nur ein Absorptionstreif wahrnehmbar und dieser sehr schwach. Die Lösung enthält weniger als 0.009 Proc. Hämoglobin (bei $100^{\circ}$ trocken). Der Streifen 0 -Hb $\alpha$ liegt bei $62-64$ oder $\mathrm{D}_{\frac{4}{5} 5} \mathrm{E}$ $-\mathrm{D}_{\frac{4}{4}} \overline{\mathrm{O}} \mathrm{E}$.

\ 3. Zwei Absorptionstreifen werden sichtbar bei einem Gehalt von etwa 0.01 Proc., doch ist $0-\mathrm{Hb}_{\beta} \beta$ sehr schwach und namentlich nach $\mathrm{E}$ zu sehr verwachsen. 0 -Hbce liegt bei $61-64$ oder $\mathrm{D}_{\frac{8}{40}} \mathrm{E}$ - $\mathrm{D}_{\frac{9}{40} \mathrm{E}}$ und $\mathrm{O}-\mathrm{Hb} \beta$ etwa bei $72-77$ oder $\mathrm{D} \frac{5}{8} \mathrm{E}-\mathrm{D} \frac{3}{8} \mathrm{E}$.

》 4. Beim Zunehmen der Concentration steigt die Intensität von $\mathrm{O}$-Hbce schneller als die von $\mathrm{O}-\mathrm{Hb} \beta$. Es tritt nur eine geringe Verbreiterung von $0-\mathrm{Hb} \beta$ ein. Die Lage ist bei 0.09 Proc.: 0 -Hbr wie Fig. $3,0-\mathrm{Hb} \beta$ von $72-78$ oder $\mathrm{D}_{4}^{25} \mathrm{E}-\mathrm{D}_{\frac{3}{4}} \mathrm{E}$. Violett wird merklich absorbirt.

» 5. Gehalt der Lösung 0.16 Proc. Beide Streifen sind viel dunkeler und etwas breiter geworden. Violett wird stark absorbirt. $\mathrm{O}-\mathrm{Hb} \alpha$ liegt bei $60 \frac{1}{2}-64 \frac{1}{2}$ oder $\mathrm{D}_{\overline{2}} \mathrm{E}-\mathrm{D}_{\frac{1}{2} \overline{2}} \mathrm{E}$ and $\mathrm{O}-\mathrm{Hb} \beta$ bei $72-78 \frac{1}{2}$ oder $\mathrm{D}_{\frac{25}{4}} \mathrm{E}-\mathrm{D} \frac{38}{4} \mathrm{E}$. Auch Blau wird absorbirt.

"6. Gehalt 0.37 Proc. O-Hbe erstreckt sich jetzt genau bis an D von $59 \frac{1}{2}-66$ oder $\mathrm{D}-\mathrm{D} \frac{11}{40} \mathrm{E}$ und $\mathrm{O}-\mathrm{Hb} \beta$ von $70-80$ d. i. $\mathrm{D} \frac{21}{4} \mathrm{E}$ - $\mathrm{E} \frac{1}{8}$ b. Violett ist ganz, Blau sehr stark absorbirt.

* 7. Die Streifen erscheinen gerade noch getrennt (Gehalt 0.6 Proc.), sodass bei höchst geringer Steigerung der Concentration beide zu einem breiten Absorptionsfelde verschmelzen. O-Hbc erstreckt sich jetzt über D hinaus: von $58-67$ und $0-\mathrm{Hb} \beta$ von 69-82. Die Räume 67-69 und $82-89$ sind schattig grün, das sichtbare Spectrum ist sehr klein geworden. 
Fig. 8. Gehalt 0.8 Proc. Die Concentration hat so zugenommen, dass bei der geringsten Erhöhung derselben das schattig grüne Feld 83-89 ganz schwarz wird. Die beiden Absorptionstreifen sind vereinigt und das gemeinschaftliche schwarze Feld erstreckt sich von 58 bis 83 .

^9. Gehalt 0.9 Proc. Es sind ausser dem Roth und Orange keine Farben mehr wahrzunehmen. Das rothe Spectrumende zeigt aber keine Verkürzung.

v 10. Lässt man nun die Concentration der Lösang immer mehr zunehmen, so verändert sich das Spectrum nur wenig. Allmählich verengt sich das helle Feld von beiden Seiten bis schliesslich bei einem Gehalt von 5.4 Proc. nur noch der schmale Raum von 45-50 erhellt bleibt. Nimmt die Concentration noch mehr zu, so wird er schattig, ohne sich zu verkleinern und bei 7.3 Proc. ist nur noch ein mit Mühe erkennbarer rother Schimmer vorhanden, der erlischt sowie der Procentgehalt 7.3 übersteigt. Zuv Ermittelung dieser Grenzwerthe diente eine Blutlösung, deren Hämoglobingehalt vorher bestimmt war.

"11. Spectrum des reducirten Hämoglobins, das Stokessche Reductionsband. Sehr concentrirte Lösung, doch wird viel weniger Blau und Violett und mehr Roth absorbirt als von bedeutend verdünnteren Sauerstoffhämoglobinlösungen. Das Absorptionsband, welches sich von 58-76 erstreckt, ist nicht so scharf begrenzt wie O-Hba. In seiner Mitte etwa bei $68-72$ ist oft eine dunkelere Stelle erkennbar.

„ 12. Spectrum erhalten durch Einwirkung von Blausäure oder von Cyanalkali auf $\mathrm{O} \cdot \mathrm{Hb}$; in seinem Absorptionsbande nur wenig von dem des reducirten Hämoglobins verschieden. Auch Blutlösungen und alkalische Hämatinlösungen mit Cyankalium oder Blausäure auf die Temperatur des Körpers erwärmt zeigen dieses Spectrum. Das Absorptionshand erstreckt sich von $60-78$, ist nicht scharf begrenzt und hat seine dunkelste Stelle bei 70-74. Violett und Blau sind viel stärker, Roth weniger absorbirt als beim reducirten Hämoglobin.

» 13. Spectrum des reducirten Hämatins (Stokes), welches man erhält wenn Sohwefelalkalien auf Hämoglobin in gelinder Wärme oder in concentrirten Lösungen bei gewöhnlicher Temperatur einwirken. Der erste Absorptionstreifen Htnc ist ganz ausserordentlich intensiv schwarz und sehr scharf begrenzt; er erstreckt sich von $D_{\frac{14}{40}} \mathrm{E}-\mathrm{D}_{40}^{24} \mathrm{E}$, der zweite weniger schwarze und nicht so scharf begrenzte, der auch bei steigender Concentration der verdünnten Lösungen später erseheint, liegt bei $\mathrm{D}_{4}^{3} \mathbf{4} \mathrm{E}-$ Esb. Beim Kochen der Lösungen werden beide Streifen unsichtbar um beim Abkühlen wieder zu erscheinen. 
Fig. 14. Spectrum erhalten durch Einwirkung von Cyankalium anf sauerstofffreies Hämoglobin unter Luftabschluss. Es entsteht auch, wenn man die Lösungen von Fig. 12 mit reducirenden Mitteln behandelt und geht beim Schütteln der Lösung mit atmosphärischer Luft über in das Fig. 12 abgebildete Spectrum. Der eine Absorptionstreifen liegt bei $64-70$ d. i. $D_{4}^{\frac{1}{4}} \mathrm{E}-\mathrm{D}_{\frac{1}{2}} \mathrm{E}$, der andere bei $74-81 \frac{1}{2}$ d. i. $D \frac{3}{4} \mathrm{E}-\mathrm{E}_{\frac{1}{2}} \mathrm{~b}$. Die weitere Unterscheidung dieses Spectrum von dem Fig. 13 sbgebildeten siehe im ersten Theil meiner »Blausäure S. 86.

` 15. Spectrum des Kohlenoxydhämoglobins. KohlenoxydhämoglobinKrystalle in Wasser gelöst. Der eine Streifen $\mathrm{CO}-\mathrm{Hb}$ a liegt bei 62-68 oder $\mathrm{D} \frac{1}{8} \mathrm{E}$ - D $\frac{1}{4} \frac{7}{0} \mathrm{E}$, der andere $\mathrm{CO}-\mathrm{Hb} \beta$ bei $73-81$ oder $\mathrm{D}_{4}^{\frac{2}{4}} \mathbf{E} \mathbf{E}-\mathbf{E}_{8}^{3} \mathrm{~b}$. Gehalt der Lösung ungefähr 0.4 Proc.

„16. Spectrum einer Sauerstoffhämoglobinlösung, welche nach Behandlung mit Kohlensäure an der Luft methämoglobinhaltig geworden ist. Das Methämoglobinband liegt bei $47-521$. Es hat eine andere Lage als das Essigsäureband. 


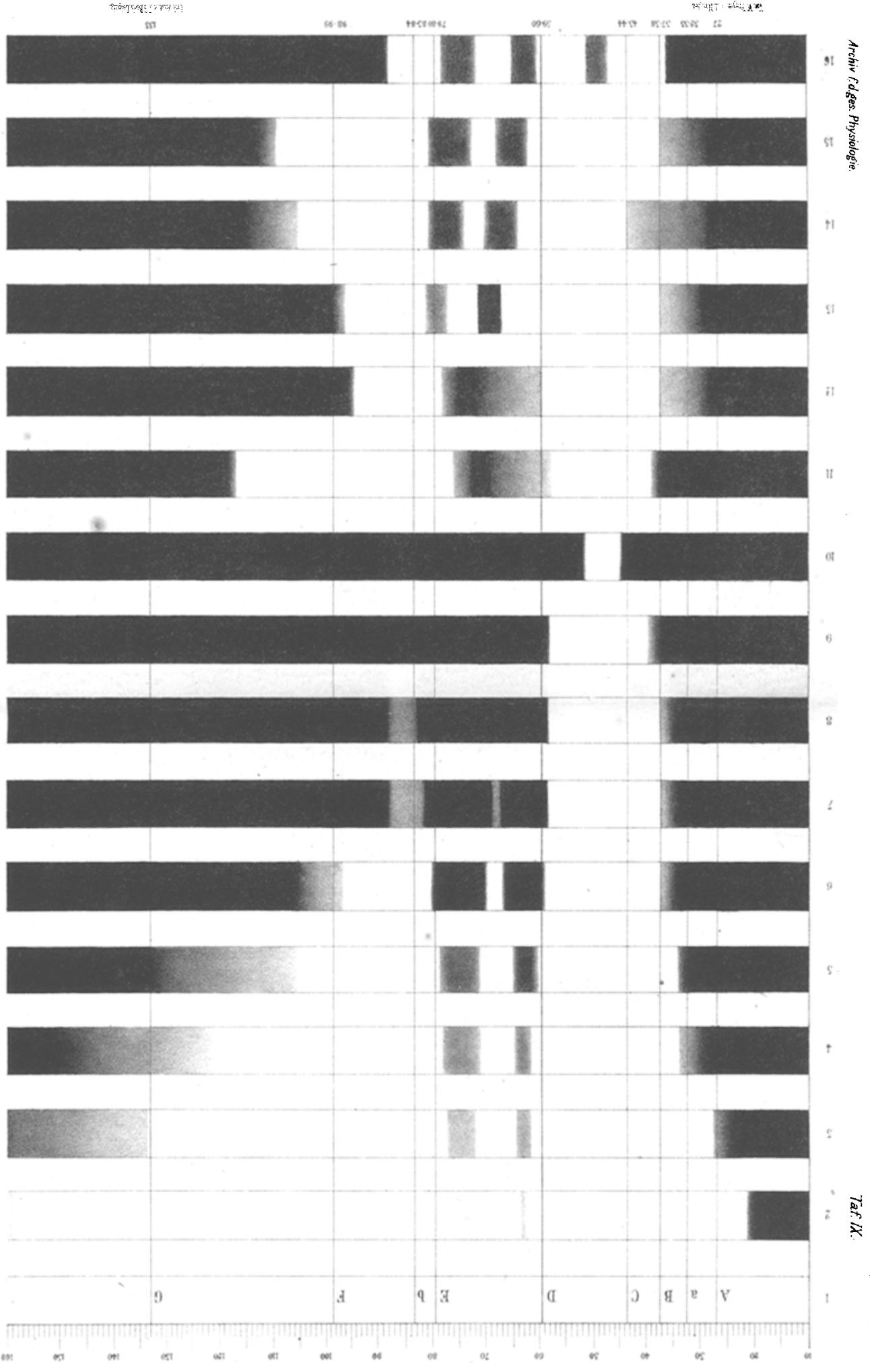

